CAMP Working Paper Series

No 4/2016

Words are the new numbers:

A newsy coincident index of business cycles

Leif Anders Thorsrud

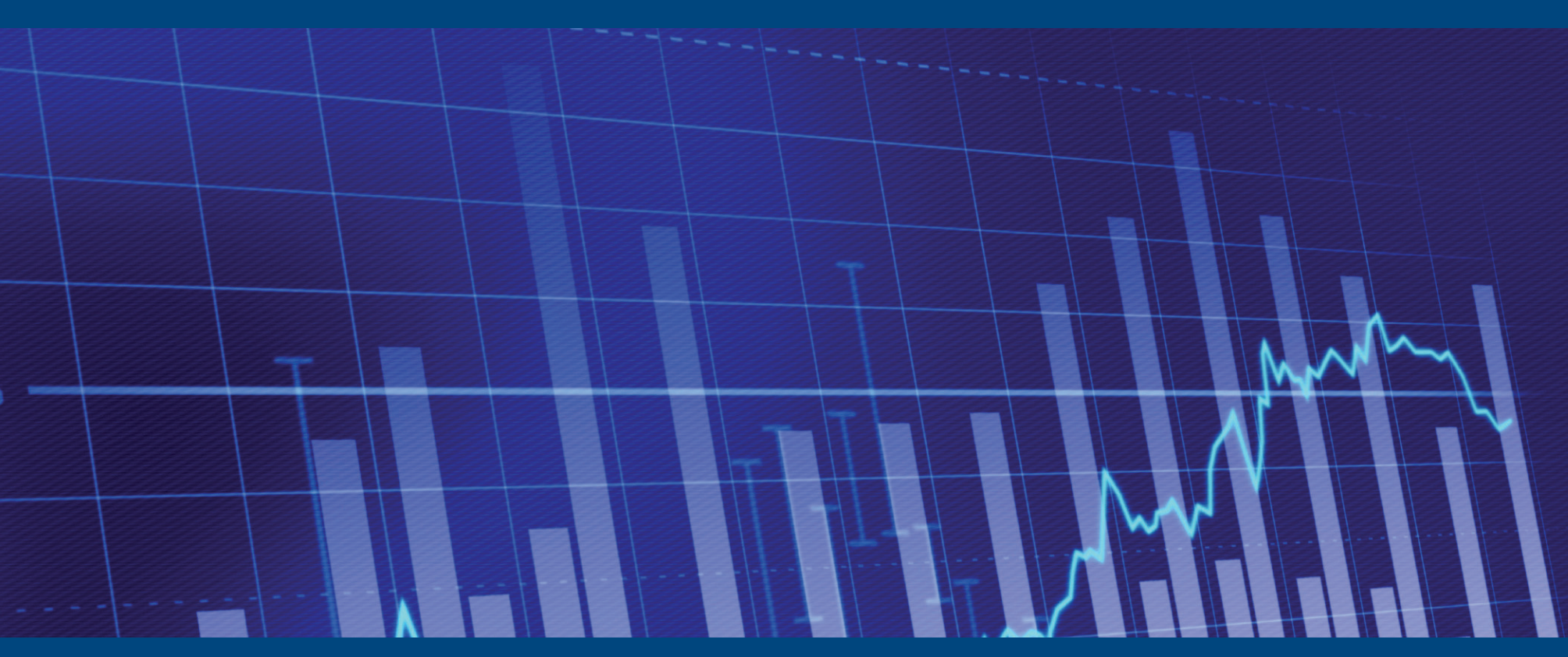

(C) Authors 2016

This paper can be downloaded without charge from the CAMP website http://www.bi.no/camp 


\title{
Words are the new numbers: A newsy coincident index of business cycles*
}

\author{
Leif Anders Thorsrud ${ }^{\dagger}$
}

February 15, 2016

\begin{abstract}
In this paper I construct a daily business cycle index based on quarterly GDP and textual information contained in a daily business newspaper. The newspaper data is decomposed into time series representing newspaper topics using a Latent Dirichlet Allocation model. The business cycle index is estimated using the newspaper topics and a time-varying Dynamic Factor Model where dynamic sparsity is enforced upon the factor loadings using a latent threshold mechanism. I show that both contributions, the usage of newspaper data and the latent threshold mechanism, contribute towards the qualities of the derived index: It is more timely and accurate than commonly used alternative business cycle indicators and indexes, and, it provides the index user with broad based high frequent information about the type of news that drive or reflect economic fluctuations.
\end{abstract}

\section{JEL-codes: C11, C32, E32}

Keywords: Business cycles, Dynamic Factor Model, Latent Dirichlet Allocation (LDA)

*This paper is part of the research activities at the Centre for Applied Macro and Petroleum economics (CAMP) at the BI Norwegian Business School. I thank Hilde C. Bjørnland, Pia Glæserud and Vegard Larsen for valuable comments. Vegar Larsen has also provided helpful technical assistance for which I am grateful. The views expressed are those of the author. The usual disclaimer applies.

${ }^{\dagger}$ Centre for Applied Macro and Petroleum economics, BI Norwegian Business School. Email: leif.a.thorsrud@bi.no 


\section{Introduction}

For policy makers and forecasters it is vital to be able to access the state of the economy in real-time to devise appropriate policy responses and condition on an updated information set. However, in real-time, our best known measure of economic activity, GDP growth, is not observed as it is registered on a quarterly frequency and published with a considerable lag, usually up to at least one month. Various more timely indicators (like financial and labour market data) are monitored closely, and coincident indexes constructed, to mediate these caveats. ${ }^{1}$

However, existing approaches face at least two drawbacks. First, the relationships between the timely indicators typically monitored, e.g., financial market data, and GDP growth are inherently unstable, see, e.g., Stock and Watson (2003). Second, due to limited availability of high frequent data, the type of data from which coincident indexes often are constructed is constrained. As a result, changes in any coincident index constructed from such series do generally not give the index user broad information about why the index change? For example, changes in financial returns are timely observed and commonly believed to be due to new information about future fundamentals, but the changes themselves do not reveal what this new information is. For policy makers in particular, as reflected in the broad coverage of various financial and macroeconomic data in monetary policy reports and national budgets, understanding why the index change might be equally important as the movement itself. Related to this, the timely indicators often used are typically obtained from structured databases and professional data providers. In contrast, the agents in the economy likely use a plethora of high frequent information to guide their actions and thereby shape aggregate economic fluctuations. It is not a brave claim to assert that this information is highly unstructured and does not come (directly) from professional data providers, but more likely reflect information shared, generated, or filtered through a large range of channels, including media.

In this paper I propose a new coincident index of business cycles aimed at addressing the drawbacks discussed above. In the tradition of Mariano and Murasawa (2003) and Aruoba et al. (2009), I estimate a latent daily coincident index using a Bayesian timevarying Dynamic Factor Model (DFM) mixing observed daily and quarterly data. To this, I make two contributions. First, the daily data set comes from a novel usage of textual information contained in a daily business newspaper, represented as topic frequencies

\footnotetext{
${ }^{1}$ Stock and Watson (1988) and Stock and Watson (1989) provide early examples of studies constructing coincident indexes using single frequency variables and latent factors, while Mariano and Murasawa (2003) extent this line of research to a mixed frequency environment using monthly and quarterly data. Later contributions mixing even higher frequency data, e.g., daily, with quarterly observations are given by, e.g., Evans (2005) and Aruoba et al. (2009).
} 
across time. Thus, words are the new numbers, and the name: A newsy coincident index of business cycles $(N C I)$. In turn, this innovation allows for decomposing the changes in the latent daily business cycle index into the (time-varying) news components it constitutes, and therefore also say something more broadly about why (in terms of news topics) the index changes at particular points in time. My hypothesis is simple: To the extent that the newspaper provides a relevant description of the economy, the more intensive a given topic is represented in the newspaper at a given point in time, the more likely it is that this topic represents something of importance for the economy's current and future needs and developments. Instead of relying on a limited set of conventional high frequency indicators to measure changes in business cycle conditions, I use a primary source for new broad based information directly - the newspaper. ${ }^{2}$

Second, building on the Latent Threshold Model (LTM) idea introduced by Nakajima and West (2013), and applied in a factor model setting in Zhou et al. (2014), the DFM is specified using an explicit threshold mechanism for the time-varying factor loadings. This enforces sparsity onto the system, but also explicitly takes into account that the relationship between the latent daily business cycle index and the indicators used to derive it might be unstable (irrespective of whether newspaper data or more standard high frequent data is used to derive the index).

My main results reflect that both innovations listed above are important. I show, using Receiver Operating Characteristic (ROC) curves, that compared to more traditional business cycle indicators and coincident indexes, the $N C I$ provides a more timely and trustworthy signal about the state of the economy. This gain is achieved through the combined usage of newspaper data and allowing for time-variation in the factor loadings. Moreover, the NCI contains important leading information, suggesting that the $N C I$ would be a highly useful indicator for turning point predictions and nowcasting. Decomposing the $N C I$ into the individual news topic contributions it constitutes reveals that on average, across different business cycle phases, news topics related to monetary and fiscal policy, the stock market and credit, and industry specific sectors seem to provide the most important information about business cycle conditions. Finally, the sign and timing of their individual contributions map well with the historical narrative we have about recent business cycle phases.

In using newspaper data the approach taken here shares many features with a growing number of studies using textual information to predict and explain economic outcomes,

\footnotetext{
${ }^{2}$ Economic theory suggests that news might be important for explaining economic fluctuations because it contains new fundamental information about the future, see, e.g., Beaudry and Portier (2014). Alternatively, as in, e.g., Angeletos and La'O (2013), news is interpreted as some sort of propagation channel for sentiment. Results reported in Larsen and Thorsrud (2015) indicate that information in the newspaper, represented as topic frequencies, contain new fundamental information about the future.
} 
but extends this line of research it into the realm of coincident index construction. For example; Tetlock (2007) and Soo (2013) subjectively classify textual information using negative and positive word counts, and link the derived time series to developments in the financial and housing market; Bloom (2014) summarizes a literature which constructs aggregate uncertainty indexes based on (among other things) counting pre-specified words in newspapers; Choi and Varian (2012) use Google Trends and search for specific categories to construct predictors for present developments in a wide range of economic variables.

In this paper, textual information is utilized using a Latent Dirichlet Allocation (LDA) model. The LDA model statistically categorizes the corpus, i.e., the whole collection of words and articles, into topics that best reflect the corpus's word dependencies. A vast information set consisting of words and articles can thereby be summarized in a much smaller set of topics facilitating interpretation and usage in a time series context. ${ }^{3}$ Compared to existing textual approaches, the LDA approach offers several advantages. In terms of word counting, what is positive words and what negative obviously relates to an outcome. A topic does not. A topic has content in its own right. Moreover, choosing the words or specific categories to search for to be able to summarize aggregate economic activity is not a simple task. Instead, the LDA machine learning algorithm automatically delivers topics that describe the whole corpus, permitting us to identify the type of new information that might drive or reflect economic fluctuations. In Larsen and Thorsrud (2015) it is shown that individual news topics extracted using a LDA model adds marginal predictive power for a large range of economic aggregates at a quarterly frequency. Here I build on this knowledge and use similar topics to construct the daily NCI.

The perhaps most closely related paper to this is Balke et al. (2015). They use customized text analytics to decompose the Beige Book, a written description of economic conditions in each of the twelve districts banks of the Federal Reserve System in the U.S, into time series and construct a coincident index for the U.S. business cycle. They find that this textual data source contains information about current economic activity not contained in quantitative data. Their results are encouraging and complement my findings. However, the Beige Book is published on an irregular frequency, and not all countries have Beige Book type of information. In contrast, most countries have publicly available newspapers published (potentially) daily. ${ }^{4}$ Finally, as alluded to above, in contrast to

\footnotetext{
${ }^{3}$ Blei et al. (2003) introduced the LDA as a natural language processing tool. Since then the methodology has been heavily applied in the machine learning literature and for textual analysis. Surprisingly, in economics, it has hardly been applied. See, e.g., Hansen et al. (2014) for an exception.

${ }^{4}$ In relation to this, the U.S is in many aspects a special case when it comes to quantitatively available economic data simple because there are so many of them available at a wide variety of frequencies. For most other countries, this is not the case. The usage of daily newspaper data can potentially mitigate such missing information.
} 
existing studies using textual data, with the news topic approach one can decompose the daily changes in the coincident index into news topic contributions.

The rest of this paper is organized as follows. Section 2 describes the newspaper data, the topic model, and the estimated news topics. The mixed frequency and time-varying DFM is described in Section 3. Results are presented in Section 4. Section 5 concludes.

\section{Data}

The raw data used in this analysis consists of a long sample of the entire newspaper corpus for a daily business newspaper and quarterly GDP growth for Norway. I focus on Norway because it is a small and open economy and thereby representative of many western countries, and because small economies, like Norway, typically have only one or two business newspapers, making the choice of corpus less complicated. Here, I simply choose the corpus associated with the largest and most read business newspaper, Dagens Naringsliv (DN), noting that DN is also the fourth largest newspaper in Norway irrespective of subject matter. DN was founded in 1889, and has a right-wing and neoliberal political stance. Importantly, however, the methodology for extracting news from newspaper data, and analyse whether or not it is informative about business cycle developments, is general and dependant neither on the country nor newspaper used for the empirical application.

To make the textual data applicable for time series analysis, the data is first decomposed into time series of news topics using a Latent Dirichlet Allocation (LDA) model. The newspaper corpus and the LDA usage in this paper is similar to that described in Larsen and Thorsrud (2015), and I refer to their work for details. Still, as the usage of textual data and the application of a LDA model are relatively new in economics, I provide a summary of the computations below. I then examine the mapping between the estimated news topics and GDP growth using simple principal components analysis, before presenting the proposed time-varying and mixed frequency Dynamic Factor Model (DFM) in the subsequent section.

\subsection{The News Corpus, the LDA and topics}

The DN news corpus is extracted from Retriever's "Atekst" database, and covers all articles published in DN from May 21988 to December 29 2014. In total this amounts to $N^{a}=459745$ articles, well above one billion words, more than a million unique tokens, and a sample of $T^{d}=9741$ days. This massive amount of data makes statistical computations challenging, but as is customary in this branch of the literature some steps are taken to 
clean and reduce the raw dataset before estimation. A description of how this is done is given in Appendix C.

The "cleaned", but still unstructured, DN corpus is decomposed into news topics using the LDA model. The LDA model is an unsupervised learning algorithm introduced by Blei et al. (2003) that clusters words into topics, which are distributions over words, while at the same time classifying articles as mixtures of topics. The technical details on estimation and prior specification for the LDA model are described in Appendix D. The model is estimated using 7500 Gibbs simulations and $N^{T}=80$ topics are classified. Marginal likelihood comparisons across LDA models estimated using smaller numbers of topics, see Larsen and Thorsrud (2015), indicate that 80 topics provide the best statistical decomposition of the DN corpus.

Now, the LDA estimation procedure does not give the topics any name or label. To do so, labels are subjectively given to each topic based on the most important words associated with each topic. As shown in Table 3 in Appendix A, which lists all the estimated topics together with the most important words associated with each topic, it is, in most cases, conceptually simple to classify them. I note, however, that the labelling plays no material role in the experiment, it just serves as a convenient way of referring to the different topics (instead of using, e.g., topic numbers or long lists of words). What is more interesting, however, is whether the LDA decomposition gives a meaningful and easily interpretable topic classification of the DN newspaper. As illustrated in Figure 1, it does: The topic decomposition reflects how DN structures its content, with distinct sections for particular themes, and that DN is a Norwegian newspaper writing about news of particular relevance for Norway. We observe, for example, separate topics for Norway's immediate Nordic neighbours (Nordic countries); largest trading partners (EU and Europe); and biggest and second biggest exports (Oil production and Fishing). A richer discussion about a similar decomposition is provided in Larsen and Thorsrud (2015).

\subsection{News Topics as time series}

Given knowledge of the topics (and their distributions), the topic decompositions are translated into time series. To do this, I proceed in three steps.

Step 1. For each day, the frequency with which each topic is represented in the newspaper that day is calculated. By construction, across all topics, this number will sum to one for any given day. On average, across the whole sample, each topic will have a more or less equal probability of being represented in the newspaper. Across shorter time periods, i.e., days, the variation can be substantial. I define this as the $D_{0}$ data set, which will be a $T^{d} \times N^{T}$ matrix. ${ }^{5}$

\footnotetext{
${ }^{5}$ Since DN is not published on Sundays, but economic activity also takes place on Sundays, missing
} 


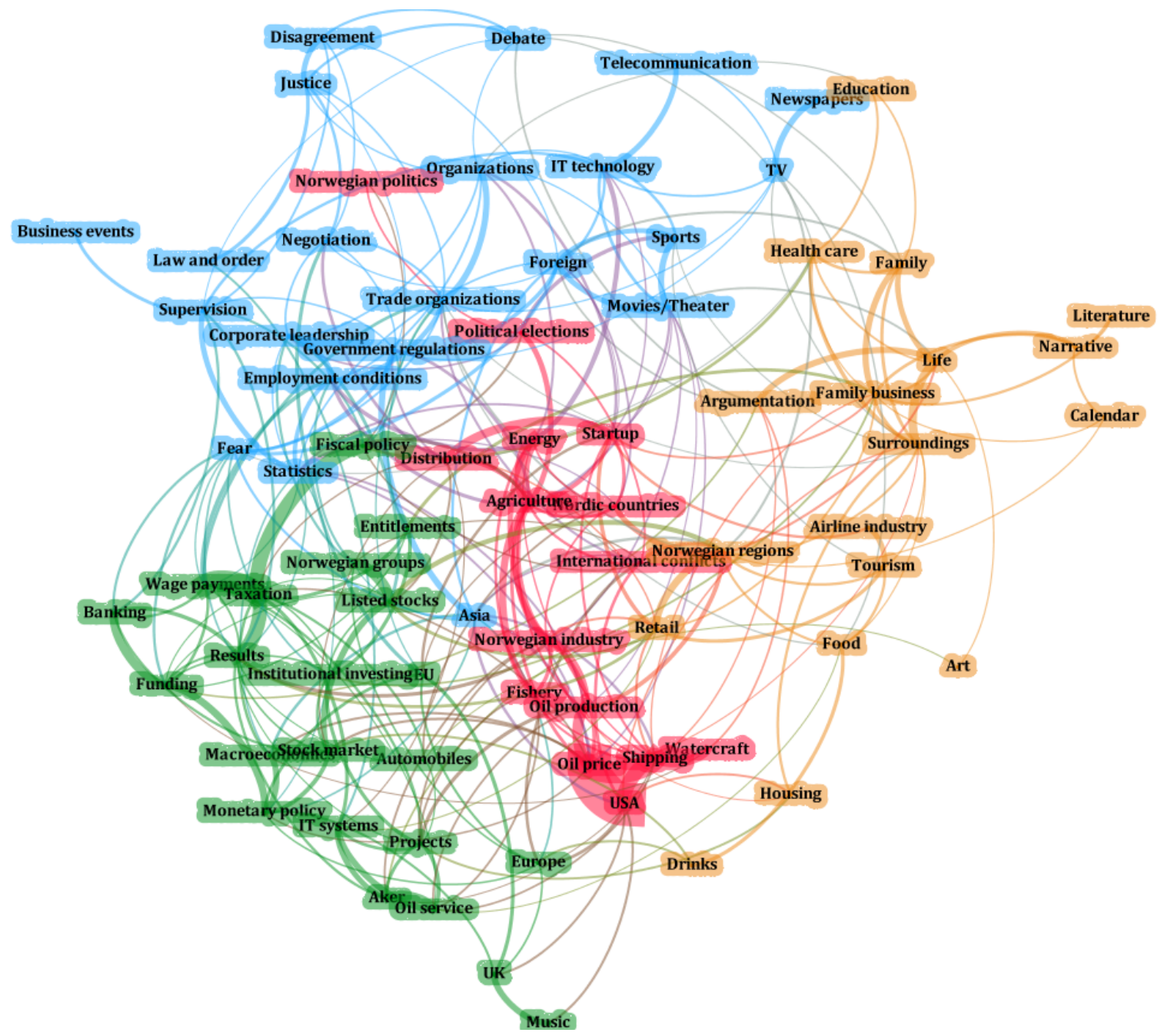

Figure 1. A Network representation of the estimated news topics. The nodes in the graph represent the identified topics. All the edges represent words that are common to the topics they connect. The thickness of the edges represents the importance of the word that connect the topics, calculated as edge weight $=1 /$ (ranking of word in second topic + ranking of word in first topic). The topics with the same colour are clustered together using a community detection algorithm called Louvain modularity. Topics for which labelling is Unknown, c.f. Table 3 in Appendix A, are removed from the graph for visual clarity.

Step 2. Since the time series objects constructed in Step 1 will be intensity measures, i.e., reflecting how much DN writes about a given topic at a specific point in time, their tone is not identified. That is, whether the news is positive or negative. To mediate this, a sign identified data set based on the number of positive relative to negative words in the text is constructed. In particular, for each day $t$, all $N_{t}^{a}$ newspaper articles that day, and each news topic $i=1, \ldots, N^{T}$ in $D_{0}$, the article that news topic $i$ describes the best is found. Given knowledge of this topic article mapping, positive/negative words in the articles are identified using an external word list, the Harvard IV-4 Psychological Dictionary, and simple word counts. ${ }^{6}$ The count procedure delivers two statistics for each observations are filled by simple linear interpolation.

${ }^{6}$ Counting the number of positive and negative words in a given text using the Harvard IV-4 Psychological 
(a) Monetary Policy (72)

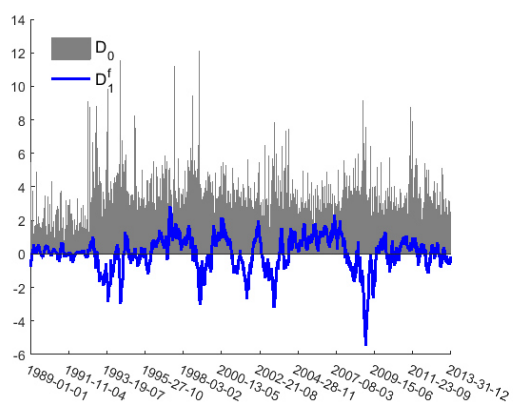

(d) Results (46)

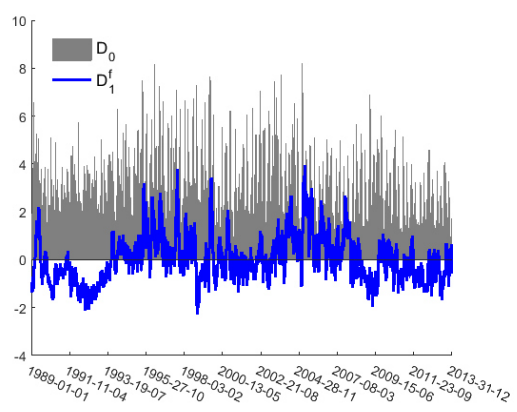

(b) Retail (60)

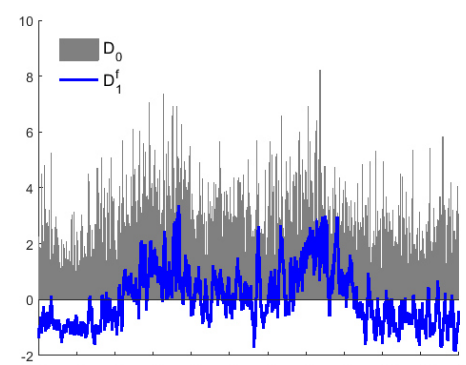

(1)

(e) Startup (61)

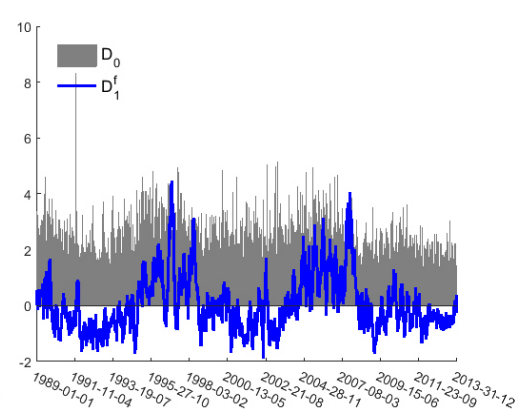

(c) Funding (42)

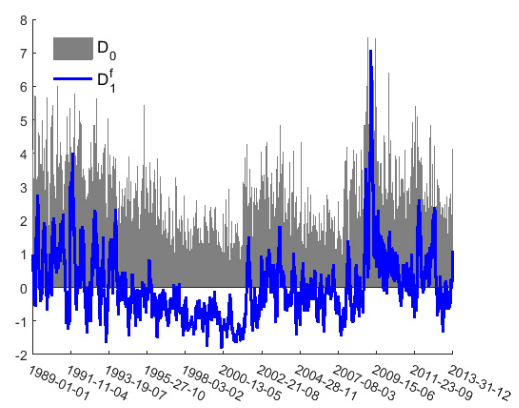

(f) Statistics (44)

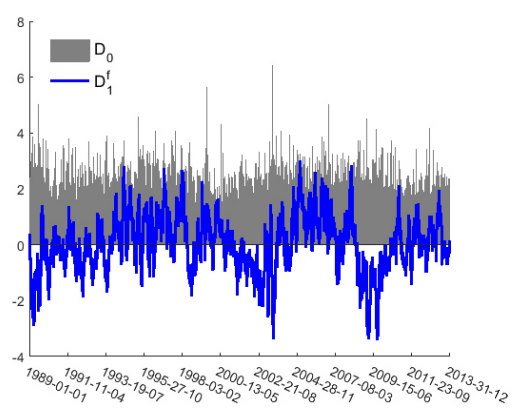

Figure 2. Individual news topics (topic numbers, confer Table 3 in Appendix A, in parenthesis). The grey bars and blue lines report topic time series from the $D_{0}$, and $D_{1}^{f}$ data sets, respectively. See the text for details.

article, containing the number of positive and negative words. These statistics are then normalized such that each article observation reflects the fraction of positive and negative words, i.e.:

$$
\text { Pos }_{t, n^{a}}=\frac{\# \text { positivewords }}{\# \text { totalwords }} \quad \operatorname{Neg}_{t, n^{a}}=\frac{\# \text { negativewords }}{\# \text { totalwords }}
$$

The overall mood of article $n^{a}$, for $n^{a}=1, \ldots, N_{t}^{a}$ at day $t$, is defined as:

$$
S_{t, n^{a}}=\operatorname{Pos}_{t, n^{a}}-N e g_{t, n^{a}}
$$

Using the $S_{t, n^{a}}$ statistic and the topic article mapping described above, the sign of each topic in $D_{0}$ is adjusted accordingly as $D_{1}=S_{t, n^{a}} D_{t, \tilde{i}, 0}$, where $\tilde{i}$ reflects that article $n^{a}$ is mapped to topic $i$.

Step 3. To remove daily noise from the topic time series in the $D_{1}$ data set, each topic time series is filtered using a 60 day (backward looking) moving average filter. The final data sets used in the subsequent analysis are made trend stationary by removing a simple linear trend, and standardized to facilitate the factor model analysis. For future reference Dictionary is a standard methodology in this branch of the literature, see, e.g., Tetlock (2007). However, the Harvard IV-4 Psychological Dictionary word list contains English words only, which need to be translated to Norwegian. The final set of words used here consists of 40 positive and 39 negative Norwegian words. The translated word list can be obtained upon request. 
I label this data set $D_{1}^{f} \cdot 7$

Figure 2 reports six of the topic time series, and illustrates how the different steps described above affect the data. The grey bars show the data as topic frequencies across time, i.e., as constructed in Step 1 above. As is clearly visible in the graphs, these measures are very noisy. Applying the transformations described in Step 2 and Step 3 changes the intensity measures into sign identified measures and removes much of the most high frequent movements in the series. As seen from the figures, the differences between the $D_{0}$ and $D_{1}^{f}$ measures are sometimes substantial, highlighting the influence of the sign identification procedure. The effect on the Monetary Policy topic is particular clear. From Figure 2 we also observe that topics covary, at least periodically. The maximum (minimum) correlation across all topics is $0.57(-0.40)$ using the $D_{1}^{f}$ data set. However, overall, the average absolute value of the correlation among the topics is just 0.1 , suggesting that different topics are given different weight in the DN corpus across time.

\section{$2.3 \quad$ GDP and news}

Gross Domestic Product for mainland Norway, measured in constant 2012 prices (million NOK), is obtained from Statistics Norway (SSB). ${ }^{8}$ The raw series is transformed to quarterly growth rates. Prior to estimation, the local mean of the growth rates is removed using a linear time trend, and the series is standardized. In the rest of this paper the raw quarterly growth rates will be referred to as $G D P$, and the adjusted version, used for estimation, as $G D P^{a}$.

How do the news topics relate to $G D P^{a}$ ? To get a first pass impression I compute the first principal component of the sign identified data set, $D_{1}^{f}$, using either all 80 topics (PCA1), or only the 20 topics most correlated with linearly interpolated daily $G D P^{a}$ (PCA2), see Table 3 in Appendix A. These single common components explain only roughly 12 and 27 percent, respectively, of the overall variation in the data set, but seems to capture important business cycle fluctuations surprisingly well, see Figure 3. However, the factors derived from the simple PCA analysis do not seem to move in tandem with output during the early and later part of the sample. In addition, they are far from able to track the more high frequent movements in output. Having said this, it is still interesting that an unsupervised LDA and PCA decomposition of a business newspaper

\footnotetext{
7 The estimated NCI, see Section 4, becomes more (less) noisy if a shorter (longer) window size is used to smooth the news topics (for similar prior specifications), but the overall cyclical pattern remains the same. I have also experimented using other word count and topic article mappings to construct the $D_{1}$ data set (in Step 2), observing that the methodology described above works best. Details about these alternative transformations can be obtained on request.

${ }^{8}$ In Norway, using GDP excluding the petroleum sector is the commonly used measure of economic activity. I follow suit here because it facilitates the formal evaluation of the NCI in Section 4.
} 


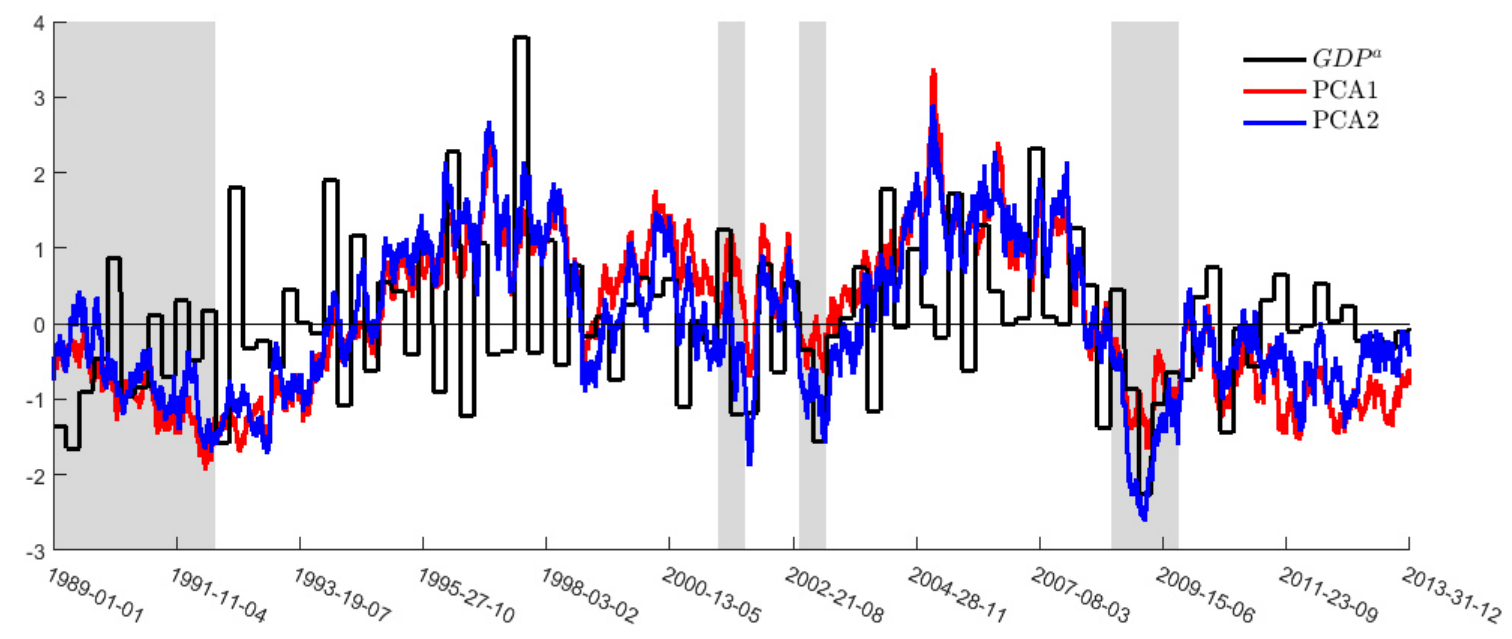

Figure 3. $G D P^{a}$ is recorded at the end of each quarter, but reported on a daily basis in the graph using previous end-of-period values throughout the subsequent quarter. The red and blue lines are the first principal component estimate of the $D_{1}^{f}$ data set using 80 and 20 topics, respectively. Recession periods, defined by a $M S-F M Q$ model, see Section 4.1, are illustrated using grey colour shading.

provides information about $G D P^{a}$ in the manner reported here. It is not only a novel finding in itself, but also motivates the usage of a more supervised factor model using this type of data. I turn to this next.

\section{The Dynamic Factor Model}

To estimate a coincident index of business cycles utilizing the joint informational content in quarterly output growth and daily news topic series I build on Mariano and Murasawa (2003) and Aruoba et al. (2009) and develop a mixed frequency time-varying Dynamic Factor Model (DFM).

Measured at the highest frequency among the set of mixed frequency observables, which is daily in this analysis, the DFM can be written as:

$$
\begin{aligned}
& y_{t}=z_{0, t} a_{t}+\cdots+z_{s, t} a_{t-s}+e_{t} \\
& a_{t}=\Phi_{1} a_{t-1}+\cdots+\Phi_{h} a_{t-h}+\epsilon_{t} \\
& e_{t}=\Phi_{1} e_{t-1}+\cdots+\Phi_{p} e_{t-p}+u_{t}
\end{aligned}
$$

Equation (3a) is the observation equation of the system. $y_{t}$ is a $N \times 1$ vector of observable and unobservable variables assumed to be stationary with zero mean. Here, $y_{t}$ contains (unobserved) daily output growth and (observed) daily newspaper topic time series. $z_{j, t}$ is a $N \times q$ matrix with dynamic factor loadings for $j=0,1, \cdots, s$, and $s$ denotes the number of lags used for the dynamic factors $a_{t}$. The dynamic factors, containing the daily business cycle index, follow a $\operatorname{VAR}(h)$ process given by the transition equation in (3b), where $\epsilon_{t} \sim$ i.i.d.N $(0, \Omega)$. Finally, equation (3c) describes the time series process for 
the $N \times 1$ vector of idiosyncratic errors $e_{t}$. It is assumed that these evolve as independent $\operatorname{AR}(p)$ processes with $u_{t} \sim$ i.i.d.N $(0, H)$, and that $u_{t}$ and $\epsilon_{t}$ are independent. The model's only time-varying parameters are the factor loadings $\left(z_{j, t}\right)$, which are restricted to follow independent random walk processes.

Apart from the usage of newspaper data, the DFM described above is fairly standard. ${ }^{9}$ Two extensions are applied here: First, sparsity is enforced upon the system through the time-varying factor loadings using a latent threshold mechanism. Second, since the variables in the $y_{t}$ vector are observed at different frequency intervals, cumulator variables are used to ensure consistency in the aggregation from higher to lower frequencies. Below I elaborate on these two extensions. A full description of the model, and its extensions, is given in Appendix E.

\subsection{Enforcing sparsity and identification}

Following the Latent Threshold Model (LTM) idea introduced by Nakajima and West (2013), and applied in a DFM setting in Zhou et al. (2014), sparsity is enforced onto the system through the time-varying factor loadings using a latent threshold. For example, for one particular element in the $z_{0, t}$ matrix, $z_{t}$, the LTM structure can be written as:

$$
z_{t}=z_{t}^{*} \varsigma_{t} \quad \varsigma_{t}=I\left(\left|z_{t}^{*}\right| \geq d\right)
$$

where

$$
z_{t}^{*}=z_{t-1}^{*}+w_{t}
$$

In (4) $\varsigma_{t}$ is a zero one variable, whose value depends on the indicator function $I\left(\left|z_{t}^{*}\right| \geq d\right)$. If $\left|z_{t}^{*}\right|$ is above the the threshold value $d$, then $\varsigma_{t}=1$, otherwise $\varsigma_{t}=0$.

In general, the LTM framework is a useful strategy for models where the researcher wants to introduce dynamic sparsity. For example, as shown in Zhou et al. (2014), allowing for such mechanism uniformly improves out-of-sample predictions in a portfolio analysis due to the parsimony it induces. Here, the LTM concept serves two purposes. First, if estimating the factor loadings without allowing for time variation, the researcher might conclude that a given topic has no relationship with $a_{t}$, i.e., that $z=0$, simply because, on average, periods with a positive $z_{t}$ cancels with periods with a negative $z_{t}$. By using the time-varying parameter formulation above, this pitfall is avoided. Second, it is not very likely that one particular topic is equally important throughout the estimation sample.

\footnotetext{
${ }^{9}$ Similar specifications have been applied in recent work by Lopes and Carvalho (2007), Del Negro and Otrok (2008), Ellis et al. (2014), and Bjørnland and Thorsrud (2015). Some of these studies also include stochastic volatility in the DFM. In a mixed frequency setting for example, Marcellino et al. (2013) estimate a DFM (using monthly and quarterly data) without time-varying parameters, but with stochastic volatility. I abstract from this property here to focus on the innovations introduced in this paper.
} 
A topic might be very informative in some periods, but not in others. The threshold mechanism potentially captures such cases in a consistent and transparent way, safeguards against over-fitting, and controls for the fact that the relationship between the indicators and output growth might be unstable, confer the discussion in Section $1 .^{10}$

As is common for all factor models, the factors and factor loadings in (3) are not identified without restrictions. To separately identify the factors and the loadings, the following identification restrictions on $z_{0, t}$ in (3a) are enforced:

$$
z_{0, t}=\left[\begin{array}{l}
\tilde{z}_{0, t} \\
\hat{z}_{0, t}
\end{array}\right], \quad \text { for } t=0,1, \ldots, T
$$

Here, $\tilde{z}_{0, t}$ is a $q \times q$ identity matrix for all $t$, and $\hat{z}_{0, t}$ is left unrestricted. Bai and $\mathrm{Ng}$ (2013) and Bai and Wang (2012) show that these restrictions uniquely identify the dynamic factors and the loadings, but leave the $\operatorname{VAR}(h)$ dynamics for the factors completely unrestricted.

\subsection{Introducing mixed frequency variables}

Due to the mixed frequency property of the data, the $y_{t}$ vector in equation (3a) contains both observable and unobservable variables. Thus, the model as formulated in (3) can not be estimated. However, following Harvey (1990), and since the variables in $y_{t}$ are flow variables, the model can be reformulated such that observed quarterly series are treated as daily observations with missing observations. To this end, the $y_{t}$ vector is decomposed into two parts such that:

$$
y_{t}=\left(\begin{array}{l}
y_{1, t_{d}}^{*} \\
y_{2, t_{d}}
\end{array}\right)
$$

where $y_{1, t_{d}}^{*}$ is a $N_{q} \times 1$ vector of unobserved daily growth rates, mapping into quarterly growth rates as explained below, and $y_{2, t_{d}}$ a $N_{d} \times 1$ vector of other observable daily variables such that $N=N_{q}+N_{d}$. The time index $t_{d}$ is used here to explicitly state that the observations are obtained on a daily frequency. Assuming that the quarterly variables are observed at the last day of each quarter, we can further define:

$$
\tilde{y}_{1, t}= \begin{cases}\sum_{j=0}^{m} y_{1, t_{d}-j}^{*} & \text { if } \tilde{y}_{1, t} \text { is observed } \\ N A & \text { otherwise }\end{cases}
$$

where $\tilde{y}_{1, t}$ is treated as the intra-period sum of the corresponding daily values, and $m$ denotes the number of days since the last observation period. Because quarters have uneven number of days, $\tilde{y}_{1, t}$ is observed on an irregular basis. Accordingly, $m$ will vary

${ }^{10}$ The same arguments naturally applies when constructing coincident indexes using more conventional indicators (like financial and labour market developments). 
depending on which quarter and year we are in. This variation is however known, and easily incorporated into the model structure.

Given (8), temporal aggregation can be handled by introducing a cumulator variable of the form:

$$
C_{1, t}=\beta_{1, t} C_{1, t-1}+y_{1, t_{d}}^{*}
$$

where $\beta_{1, t}$ is an indicator variable defined as:

$$
\beta_{1, t}= \begin{cases}0 & \text { if } t \text { is the first day of the period } \\ 1 & \text { otherwise }\end{cases}
$$

and $y_{1, t_{d}}^{*}$ maps into the latent factor, $a_{t}$, from equation (3b). Thus, $\tilde{y}_{1, t}=C_{1, t}$ whenever $\tilde{y}_{t, 1}$ is observed, and treated as a missing observation in all other periods. Because of the usage of the cumulator variable in (9), one additional state variable is introduced to the system. Importantly, however, the system will now be possible to estimate using standard filtering techniques handling missing observations. Details are given in Appendix E.

Some remarks are in order. First, although mappings between mixed frequency variables have been applied extensively in both mixed frequency VARs and factor models, see Foroni and Marcellino (2013) for an overview, the cumulator approach has been exploited less regularly. For the purpose of this analysis it offers a clear advantage because it expands the number of state variables in the system only marginally. In contrast, using the mixed frequency approaches in, e.g., Mariano and Murasawa (2003) and Aruoba et al. (2009), would have expanded the number of state variables in the model by over 180 and 90, respectively. Such large number of states pose significant challenges for estimation, making it almost infeasible in a Bayesian context. ${ }^{11}$ Second, introducing (flow) variables of other frequencies than daily and quarterly into the system is not difficult. For each new frequency one simple constructs one new cumulator variable, specific for that frequency, and augment the system accordingly.

\subsection{Model specification and estimation}

In the model specification used to produce the main results one latent daily coincident index is identified. This latent daily coincident index is assumed to follow an $\operatorname{AR}(10)$ process, thus, $q=1$ and $h=10$. I do not allow for lags of the dynamic factors in the observation equation (3a) of the system, i.e., $s=0$. Conceptually it would have been straight forward to use higher values for $s$ for the $N_{d}$ rows in (3a) associated with the

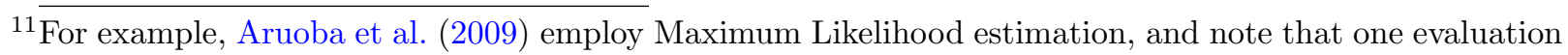
of the likelihood takes roughly 20 seconds. As Bayesian estimation using MCMC, see Section 3.3, requires a large number of iterations, the problem quickly becomes infeasible in terms of computation time.
} 
observable daily observations. However, for the $N_{q}$ rows associated with the quarterly variables, setting $s>0$ would conflict with the temporal aggregation described in Section 3.2. For all the $N$ elements in $e_{t}$, see equation 3c, the $\operatorname{AR}(p)$ dynamics are restricted to one lag, i.e., $p=1$. To avoid end point issues due to data revisions with the latest vintage of output, I restrict the estimation sample to the period 1989-01-01 to 2013-3112. Finally, based on simple correlation statistics between the news topic time series and output growth I truncate the $D_{1}^{f}$ data set to include only the 20 most correlated (in absolute value) topics, see Table 3 in Appendix A. This latter adjustment is done to ease the computational burden, but, as seen from Figure 3, unsupervised PCA estimates of the topic time series result in almost identical factor estimates irrespective of whether 20 or 80 topics are used, suggesting that 20 topics are enough. ${ }^{12}$

The time-varying DFM is estimated by decomposing the problem of drawing from the joint posterior of the parameters of interest into a set of much simpler ones using Gibbs simulations. Gibbs simulations are a particular variant of Markov Chain Monte Carlo (MCMC) methods that samples a high dimensional joint posterior by drawing from a set of lower dimensional conditional posteriors. The Gibbs simulation employed here, together with the prior specifications, are described in greater detail in Appendix E. The results reported in this paper are all based on 9000 iterations of the Gibbs sampler. The first 6000 are discarded and only every sixth of the remaining are used for inference. ${ }^{13}$

\section{A newsy coincident index of the business cycle}

Figure 4 reports the estimated NCI. As clearly seen in the upper part of the figure, the index tracks the general economic fluctuations closely. Compared to the simple PCA estimates reported in Figure 3, the $N C I$ seems to provide a better fit: It captures the low growth period in the early 1990s, the boom and subsequent bust around the turn of the century, and finally the high growth period leading up to the Great Recession. Note, however, that in Norway, the downturn in the economy following the Norwegian banking crisis in the late 1980s was just as severe as the downturn following the global financial crisis in 2008 .

An (informal) example of the importance of having timely information about the state of the economy is given in Figures $4 \mathrm{~b}$ to $4 \mathrm{~d}$. They show the benefits of the $N C I$ relative to using two timely and often used indicators; the stock index (OSEBX) and yield spreads

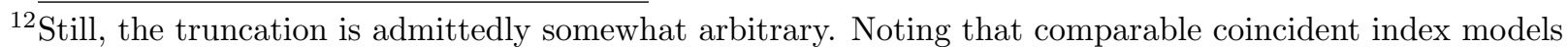
already proposed in the literature also resort to some type of variable selection prior to estimation, I leave it for future research to devise potentially more optimal methods to truncate the topics data set.

${ }^{13}$ As shown in Appendix E.7, and in Appendix E.8 for a simulation experiment, the convergence statistics seem satisfactory.
} 
(a) $N C I$ and $G D P^{a}$

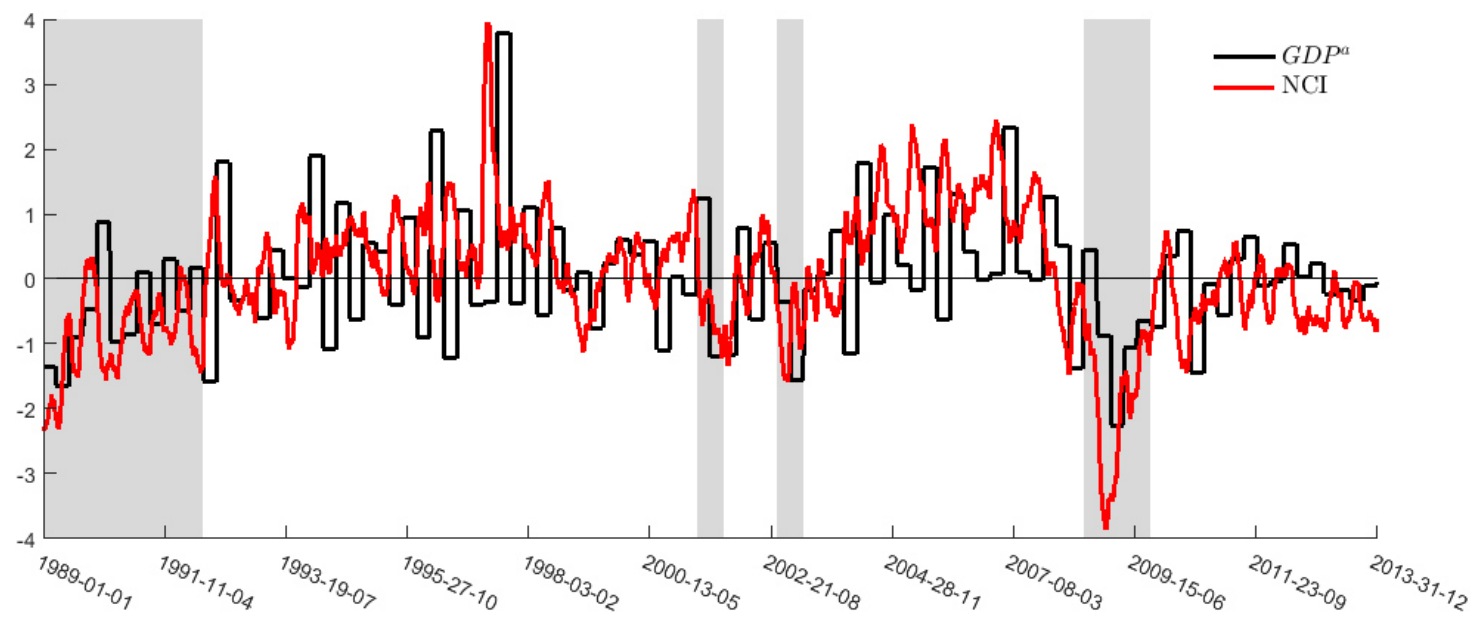

(b) 2001:Q1 - 2001:Q3

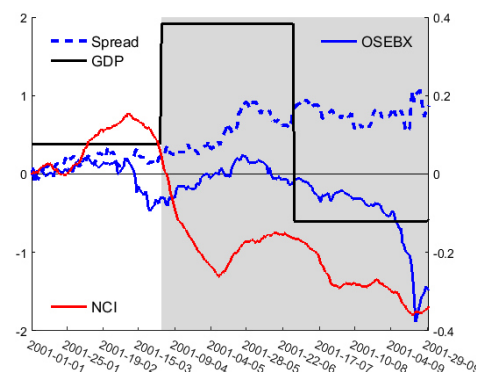

(c) 2002:Q3 - 2003:Q1

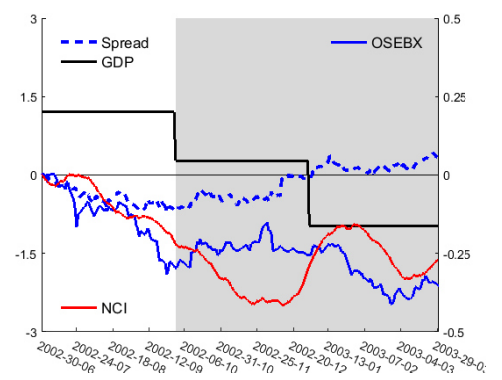

(d) 2008:Q2 - 2009:Q3

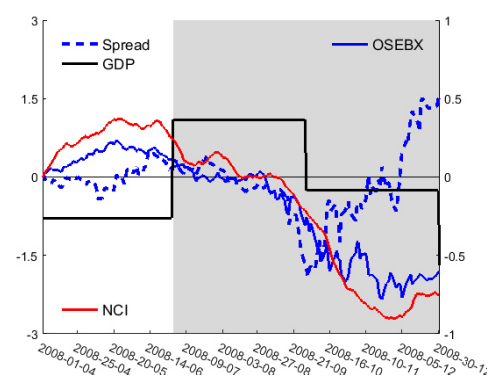

Figure 4. $G D P^{a}$ is recorded at the end of each quarter, but reported on a daily basis in the graphs using previous end-of-period values throughout the subsequent quarter. $N C I$ is the standardized measure of the daily business cycle index. Recession periods, defined by a $M S-F M Q$ model, see Section 4.1, are illustrated using grey colour shading. Figures $4 \mathrm{~b}$ to $4 \mathrm{~d}$ focuses on three specific periods where output is illustrated using $G D P$. The indicators are normalized to zero on the first day of the first quarter displayed. OSEBX is the cumulative return over the period, and Spread is the difference between the 10 year and 3 month money market interest rate.

(Spreads), see, e.g., Estrella and Mishkin (1998), around three important turning points in the Norwegian economy the last decades. For example, as seen in Figure 4d, between the second and third quarter of 2008 output growth declined considerably. During the month of August 2008, and in particular following Lehman Brothers collapse on 15 September 2008, both the stock index, the yield spread, and the NCI plummet. Since the actual number for GDP growth in the third quarter of 2008 was not known before late 2008, both leading indicators and the $N C I$ would have been useful for picking up the change in economic conditions prior to what we now know turned out to be a recession in this example. However, Figure 4d, and in particular Figures $4 \mathrm{~b}$ and 4c, also show the problem with relying on the indicators alone: Their relationship with output growth is unstable. During the recession period in the early 2000s for example, see Figure 4b, the spread did not signal any downturn at all. Likewise, for this period the changes in the stock index did not turn significantly negative before almost one quarter after the recession started. 
In contrast, for all three recession periods reported in Figure 4, the $N C I$ provides a more or less timely signal of the downturn.

\subsection{Business cycles and index evaluation}

Making a formal evaluation of the $N C I$ is challenging. By construction, the quarterly sum of the daily $N C I$ will equal the observed quarterly growth rates in $G D P^{a}$ (plus a measurement error, c.f. Section 3.2), while daily business cycle conditions, on the other hand, are not observed. Alternatively, in the tradition of Burns and Mitchell (1946), and later work by, e.g., Bry and Boschan (1971) and Hamilton (1989), to mention just two of many, aggregate economic activity can be categorized as phases of expansions and contractions, and one can assess the index's ability to classify such phases. This is the route I take here.

Following Travis and Jordà (2011), I use Receiver Operating Characteristic (ROC) curves and the area under the curve (AUROC) statistic to score the NCI's ability to classify the state of the economy. ${ }^{14}$ I do so along four dimensions: How well it categorizes business cycles using different reference cycles; how well it categorizes business cycles at a different level of time aggregation; how well it categorizes business cycles at different lags; and finally, how well it categorizes business cycles compared to other (often used and observable) alternatives? An ideal binary classifier would always indicate a recession when a recession actually occurs (true positive), while never indicate a recession when it does not occur (false positive). In Figure 5a, for example, such a classifier would be depicted by a point in the upper left corner. A model not performing any better than random guessing would end up at the 45 degree line. Thus, using the ROC one can easily compare the trade-offs (cost/benefit) one faces when using different models or indicators for classification.

Figure 5a assesses the $N C I$ 's classification ability against four different business cycle chronologies, developed by Aastveit et al. (2016) for the Norwegian economy. ${ }^{15}$ Each

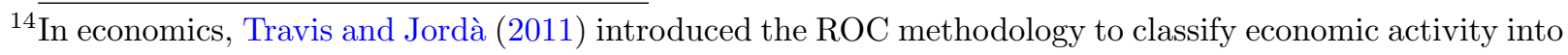
recessions and expansions. The AUROC is an often used summary statistic within the ROC framework. By definition the AUROC can not exceed 1, perfect classification, or be lower than 0.5. I compute the AUROC score non-parametrically using the algorithm described in Travis and Jordà (2011), and refer to their work for an overview of the ROC technicalities and advantages in terms of scoring business cycle chronologies. Still, as the true underlying state of the economy is never observed, even retrospectively, and since the categorization of economic activity doesn't follow any universally agreed upon law, there will be an inherent uncertainty also with this type of evaluation. An evaluation of a different sort, but perhaps more hefty, can be obtained by running a real-time out-of-sample forecasting experiment. I leave it for future research to assess the $N C I$ 's performance as an out-of-sample predictor.

${ }^{15}$ In contrast to in, e.g., the U.S, which has an official business cycle dating committee (NBER), no such 
(a) NCI and different reference cycles

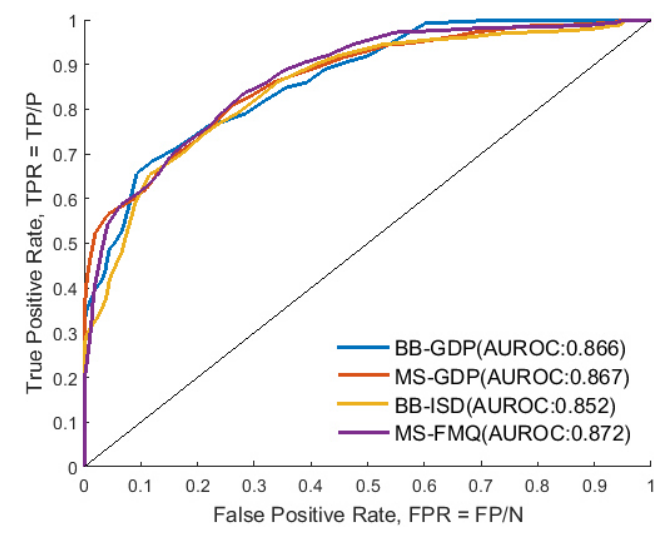

(c) NCI at various lead lengths

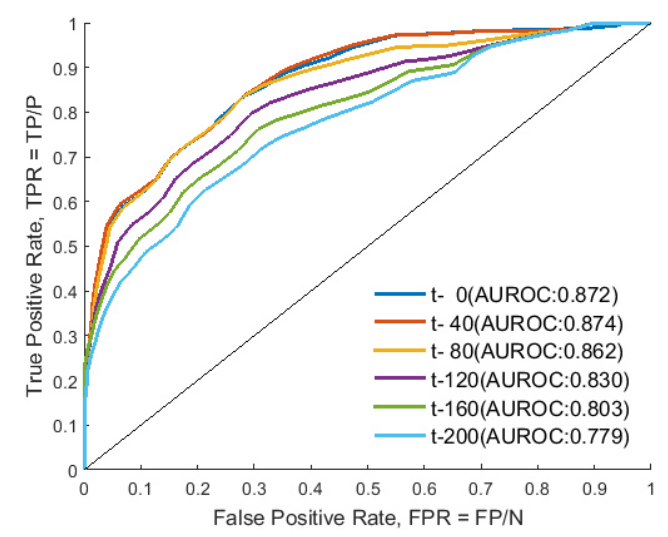

(b) NCI and quarterly classification

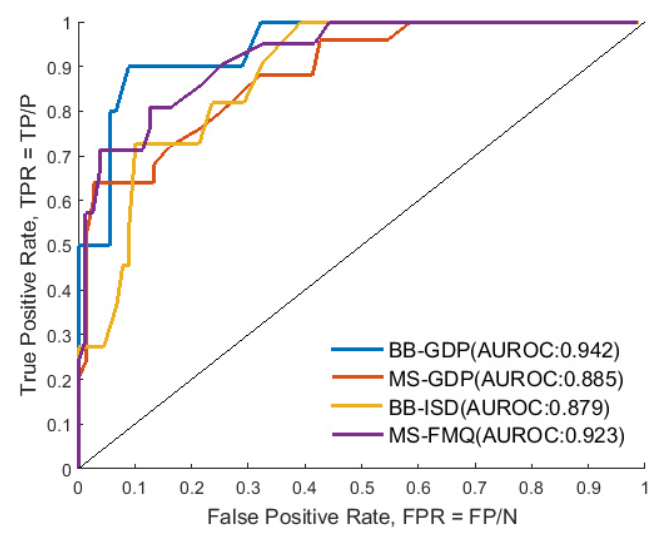

(d) NCI and alternatives

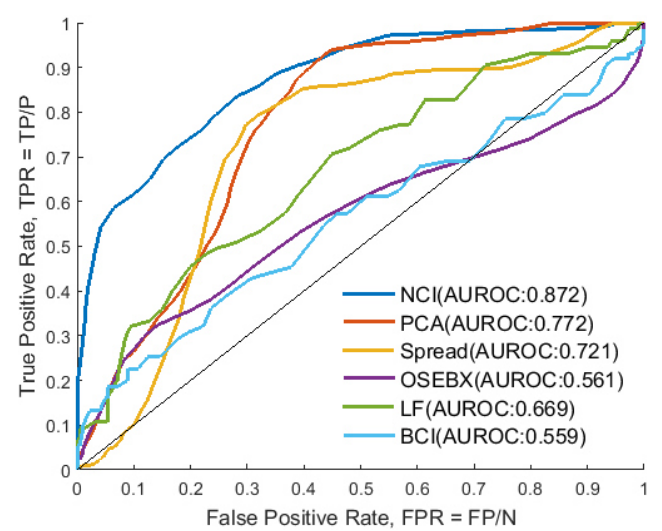

Figure 5. Receiver Operating Characteristics curves (ROC). Figure 5a reports the NCI's ability of classifying business cycle phases across four different business cycle chronologies. In Figures $5 \mathrm{~b}$ to $5 \mathrm{~d}$ the $M S-F M Q$ chronology is used as the reference cycle. Figure $5 \mathrm{~b}$ reports the results when classification is scored at a quarterly frequency. Figure $5 c$ reports the results when the $N C I$ is lagged $p=\{0,40, \ldots, 200\}$ days. Figure $5 \mathrm{~d}$ compares the performance of the daily $N C I$ against a set of daily and monthly alternatives. For the monthly indicators, $L F S$ and $B C I$, daily numbers are obtained using previous end-of-period values throughout the subsequent month.

chronology is constructed using different methodologies to extract the unobserved phases; uni- and multivariate Bry-Boschan approaches (BB-GDP and BB-ISD); a univariate Markow-switching model ( $M S-G D P)$, and a Markov-Switching factor model $(M S-F M Q)$. Aastveit et al. (2016) provide a description of these approaches and the data used. The resulting quarterly classifications, and additional model details, are summarized in Table 2 in Appendix A. ${ }^{16}$ As seen from Figure 5a, irrespective of which reference cycle that is used to define the Norwegian business cycle, the NCI yields a true positive rate of roughly 80 percent, at the cost of only 25 percent false positives. The AUROC measures are also institution or formal dating exists for Norway.

${ }^{16}$ Daily classifications are obtained by assuming that the economy remains in the same phase on each day within the quarterly classification periods. 
between 0.85 and 0.87 in all four cases, signalling very good classification. While these results are strong, but not perfect, it should be remembered that the NCI might provide an estimate of the economy's phases that is closer to the unknown truth than any of the other reference cycles I use to evaluate it. Moreover, the classification models typically used are at the quarterly (or monthly) frequency, while the $N C I$ allows for daily classification. Aggregating the $N C I$ to a quarterly time series, by simply computing the mean growth rate for each quarter, we observe that the index's classification ability becomes even better, see Figure 5b. When using the $M S-F M Q$ as the reference cycle, for example, an AUROC of 0.92 is achieved at the quarterly frequency against 0.87 at the daily frequency. Compared to the results reported for quarterly Norwegian data in Aastveit et al. (2016), and U.S. data in Travis and Jordà (2011), this score is very competitive. ${ }^{17}$

The results reported in Figure 4 indicated that the NCI had leading properties. This is confirmed more formally in Figure 5c. Lagging the NCI 40 days yields a higher AUROC score than actually using the $N C I$ as a contemporaneous classifier for the business cycle. The performance of the $N C I$ does not really start to drop before it is lagged almost one quarter (80 days), suggesting that the $N C I$ would be a highly useful indicator for turning point predictions and nowcasting.

Traditionally, coincident indexes are constructed using a number of observable daily and monthly variables. In Figure $5 \mathrm{~d}$ the classification properties of some of these variables, see Appendix A for data descriptions, are compared to the NCI. The best performing observable indicator in terms of ROC curve scoring is the daily Spread followed by the monthly labour force survey $(L F S)$. Using stock returns or the business confidence indicator $(O S E B X$ and $B C I)$ are almost no better than random guessing in terms of classifying the business cycle, confirming the impression from Figure 4. It is noteworthy that the PCA estimated news index, see Section 2.3, performs better than any of the other alternatives. At the cost of 40 percent false positive rates, it can give almost 100 percent true positive rates. Still, the AUROC score for the PCA estimated news index is well below the NCI's.

In sum, the results presented above suggest that the NCI adds value. Although other alternatives also provide information that is competitive relative to the $N C I$, these alternatives; are not necessarily available on a daily frequency; and they do not provide the users of such information any broader rational in terms of why the indicators fall or rise. As shown in the next section, the NCI does.

\footnotetext{
${ }^{17}$ Using the reference cycle generated by the $M S-F M Q$ model for Norwegian data, Aastveit et al. (2016) show that the BB-GDP model gets an AUROC of 0.93. Using U.S data, and comparing various leading indicators and coincident indexes, Travis and Jordà (2011) show that the best performing coincident index is the one developed by Aruoba et al. (2009). This index receives an AUROC of 0.96 when the NBER business cycle chronology is used as a reference cycle.
} 


\subsection{News and index decompositions}

Figure 6 illustrates how changes in the $N C I$ can be decomposed into the contributions from the individual news topics, and thereby address what type of new information underlies changes in business cycle conditions. ${ }^{18}$ To economize on space, I only report nine of the topics contributing to the $N C I$ estimate. The 11 remaining topics are reported in Figure 8 in Appendix B. Three distinct results stand out.

First, the topics listed in Figure 6 do, for the most part, reflect topics one would expect to be important for business cycles in general, and for business cycles in Norway in particular. Examples of the former are the Monetary Policy, Fiscal policy, Wage payments/Bonuses, Stock Market, Funding, and Retail topics, while the Oil production and Oil Service topics are examples of the latter. ${ }^{19}$ The remaining topics, see Figure 8 in Appendix B, are typically related to general business cycle sensitive sectors (reflected by, e.g., Airline Industry and Automobiles topics) and technological developments (reflected by, e.g., IT-technology and Startup topics). Still, although most topics are easily interpretable and provide information about what is important for the current state of the economy, some topics either have labels that are less informative, or reflect surprising categories. An example is the Life topic, reported in Figure 8. That said, such exotic or less informative named topics, are the exception rather than the rule. It is also the case that a given newspaper article contains many topics at the same time. To the extent that different topics, meaningful or not from an economic point of view, stand close to each other in the decomposition of the corpus, see Figure 1, they might covary and therefore both add value in terms of explaining the current state of the economy.

Second, while some topics seem to be important almost every period throughout the sample, other topics only contribute significantly at certain time periods. The Oil Service topic provides an example: Almost throughout the whole sample, until the mid 2000s, its contribution is close to zero. After 2004, however, its contribution becomes highly positive. Similar observations can also be confirmed for the Stock Market topic, in particular. The extended periods of zero contribution are partly due to the threshold mechanism used when estimating the time-varying factor loadings. Figure 7, in Appendix B, exemplifies how the posterior probability of a binding threshold varies substantially across time for four of the topics. It is particularly noteworthy how the "threshold probability" for the

\footnotetext{
${ }^{18}$ Technically, these results are constructed using the Kalman filter iterations and decomposing the state evolution at each updating step into news contributions, see Appendix E.5. The decompositions reported in Figure 6 are based on running the Kalman filter using the posterior median estimates of the hyperparameters and the time-varying factor loadings (at each time $t$ ).

${ }^{19}$ Norway is a major petroleum exporter, and close to 50 percent of its export revenues are linked to oil and gas. See Bjørnland and Thorsrud (2015), and the references therein, for a more detailed analysis of the strong linkages between the oil sector and the rest of the mainland economy.
} 

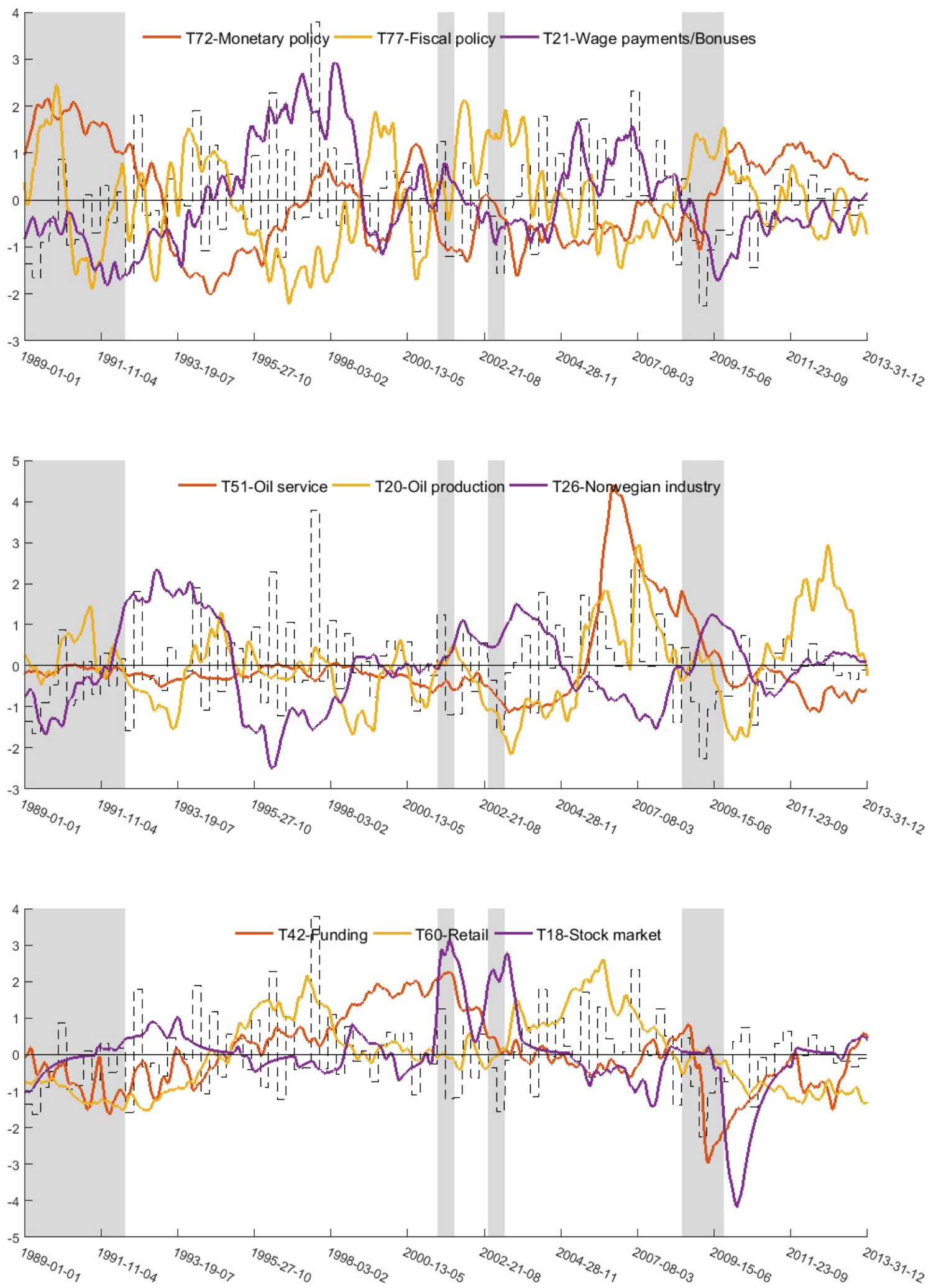

Figure 6. News topics and their (median) contribution to $N C I$ estimates across time. The news topic contributions are standardized and illustrated using different colours. GDP ${ }^{a}$, graphed using a black dotted line, is recorded at the end of each quarter, but reported on a daily basis using previous end-ofperiod values throughout the subsequent quarter. Recession periods, defined by a $M S$ - FMQ model, see Section 4.1, are illustrated using grey colour shading. 
Stock market topic varies substantially across time; perhaps capturing the conventional wisdom that the stock market predicts more recessions than what we actually observe in the data.

Third, the timing of when specific topics become important, either positively or negatively, resonates well with what we now know about the economic developments the last two decades. Without dredging to deep into the historical narrative of the Norwegian business cycle, I give three examples: It is by now well recognised that the extraordinary boom in the Norwegian economy during the 2000s was highly oil-driven. The large positive contributions from the two oil topics, Oil Service and Oil Production, reflect this. ${ }^{20}$ It is also well known that Norwegian (cost) competitiveness have declined considerable during the two last decades. According to the National Account statistics annual wages and salaries increased considerably during especially two periods; the mid 1990s and the mid/late 2000s. Both patterns are clearly visible in the graph showing how media coverage of the Wage payments/Bonuses topic contributes to the index fluctuations. Finally, we see from the bottom graph in Figure 6 that the Funding topic, a newspaper topic focused on words associated with credit and loans, contributed especially negative during the Great Recession period. Again, this resonates well with the historical narrative, given what we today know about the Great Recession episode.

It is tempting to interpret the news topics, and their contribution to the $N C I$, as some type of causal relationship between news and economic fluctuations. Technically, within the current framework, this is not a valid interpretation because the decompositions reported in Figure 6 are based on predictive properties. In stead, the newspaper topics should simply be interpreted as a broad panel of different high frequent economic indicators, informative about the current state of the economy. Still, there is a large literature emphasizing the role of news as an important channel for generating business cycles, see, e.g., Beaudry and Portier (2014) for an overview. In particular, in Larsen and Thorsrud (2015) it is shown that unexpected innovations to a quarterly news index cause persistent fluctuations in both productivity, consumption, and output. While these responses are well in line with the predictions given by the news driven business cycle view, they stand in stark contrast to those one would obtain if the informational content of the news topics were associated with some type of sentiment, see, e.g., Beaudry et al. (2011) and Angeletos and La'O (2013). It is plausible that items in the newspaper generate a self-fulfilling feedback loop where the mood of the news changes economic activity, thus validating the original sentiment.

${ }^{20}$ During the 1980s and 1990s value added in the oil service sector hardly grew in real terms (according to the National Account statistics for Norway). From the early 2000s until today, the sector has grown by over 300 percent. 
Table 1. ROC comparison across models. Each entry in the table reports the AUROC score of the benchmark NCI model relative to five alternatives across different reference cycles, confer Section 4.1. The numbers in parenthesis report the relative scores when the models are evaluated at a quarterly frequency. A value higher than one indicates that the NCI model receives a higher AUROC score. The alternative mixed frequency DFM models are: A NCI model estimated without allowing for time-varying factor loadings (NCI-F); A NCI model estimated with an augmented data set including monthly labour market data $(N C I-D M)$; A coincident index constructed without newspaper data, but with monthly labour market and confidence data, and daily spreads and returns data $(C I-D M)$; Two coincident indexes constructed without newspaper data, but with daily spreads and returns data ( $C I-D$ and $C I-F D)$. All alternative models, except $N C I-F$ and $C I-F D$, are estimated allowing for time-varying factor loadings. A description of the data used is given in Appendix A.

\begin{tabular}{lccccc}
\hline & NCI-F & NCI-DM & CI-DM & CI-D & CI-FD \\
\cline { 2 - 6 } BB-GDP & $1.22(1.22)$ & $1.36(1.24)$ & $1.36(1.24)$ & $1.17(1.04)$ & $1.38(1.45)$ \\
MS-GDP & $1.26(1.34)$ & $1.35(1.28)$ & $1.35(1.28)$ & $1.22(1.16)$ & $1.17(1.20)$ \\
BB-ISD & $1.11(1.10)$ & $1.50(1.56)$ & $1.51(1.56)$ & $1.16(1.04)$ & $1.09(1.07)$ \\
MS-FMQ & $1.23(1.30)$ & $1.29(1.26)$ & $1.30(1.27)$ & $1.25(1.16)$ & $1.20(1.24)$ \\
Average & $1.20(1.24)$ & $1.37(1.33)$ & $1.38(1.34)$ & $1.20(1.10)$ & $1.21(1.24)$ \\
\hline
\end{tabular}

\subsection{Extensions and comparisons}

In this section I do three experiments: First, I assess the importance of the LTM mechanism by estimating the DFM using the same information set as above, but without allowing for time-varying parameters. Second, I asses the importance of using a larger set of mixed frequency information by also including variables observed on a monthly frequency in the model. ${ }^{21}$ Finally, to assess how well the $N C I$ compares to other coincident indexes estimated without utilizing the daily newspaper topics, I compare its performance against three more standard alternatives.

The results from these experiments are summarized in Table 1. Across 40 different evaluations, non of the alternative specifications improve upon the benchmark NCI. On average, the benchmark NCI receives an AUROC score which is 27 (25) percent higher than the alternatives when evaluated against four different daily (quarterly) reference cycles. Focusing on the effect of including the time-varying parameter formulation we see that the benchmark model performs up to 26 (34) percent better than the alternative $N C I-F$ when the daily (quarterly) $M S-G D P$ reference cycle is used. Across all the reference cycles, the results strongly suggest that allowing for the LTM mechanism increases

${ }^{21}$ By not including more variables of lower frequency than daily in the benchmark model, the NCI model formulation departs from what's commonly used. For example, Mariano and Murasawa (2003) mix a small set of monthly variables with quarterly output growth to construct a coincident index, while Aruoba et al. (2009) mix both daily, weekly, monthly, and quarterly information to do the same. 
classification precision. Moving to the second question raised above; Including monthly information into the model does not to increase the model's classification abilities. Irrespective of which frequency and reference cycle the benchmark index is evaluated against, the $N C I$ is on average 37 (33) percent better than the alternative $N C I$-DM. Given the results presented in Figure 5, where the monthly variables themselves did not actually obtain a very high AUROC, this is perhaps not very surprising. Finally, when mixed frequency time-varying DFMs are estimated using conventional daily and/or monthly variables only, the $C I-D, C I-D M$, and $C I-F D$ models, the benchmark model is clearly better for three out of the four reference cycles used. Interestingly, comparing the results for the NCI-F model against the CI-FD model, we observe that they perform almost identical. Thus, it is the combined effect of allowing for the LTM mechanisms for the factor loadings and the usage of newspaper data which makes the NCI outperform the other alternatives. Obviously, one can not rule out that a more careful selection of other high frequent conventional variables might improve the relative score of the alternative models estimated here. On the other hand, a more careful selection of news topics might also improve the score of the $N C I$, and neither of the alternatives, $C I-D, C I-D M$, and $C I-F D$, offer the benefits in terms of news decomposition illustrated in Section 4.2.

\section{Conclusion}

In this paper I have shown how textual information contained in a business newspaper can be utilized to construct a daily coincident index of business cycles using a time-varying mixed frequency Dynamic Factor Model. The constructed index have almost perfect classification abilities, and outperforms many commonly used alternatives. This gain is achieved through the combined usage of newspaper data and allowing for time-variation in the factor loadings. The usage of newspaper data also allows for a decomposition of the coincident index into news topic contributions. I show that news topics related to monetary and fiscal policy, the stock market and credit, and industry specific sectors seem to provide the most important information about daily business cycle conditions. Moreover, the sign and timing of their individual contributions map well with the historical narrative we have about recent business cycle swings.

The (macro)economic literature utilizing textual information and alternative data sources is fast growing, but still in its early stages. Although highly data and computationally intensive, the results presented here are encouraging and motivates further research. Going forward, an assessment of the predictive power of the proposed daily coincident index, and testing the methodology across different countries and media types, are natural extensions. 


\section{References}

Aastveit, K. A., A. S. Jore, and F. Ravazzolo (2016). Identification and real-time forecasting of Norwegian business cycles. International Journal of Forecasting 32(2), 283 -292 .

Angeletos, G.-M. and J. La'O (2013). Sentiments. Econometrica 81(2), 739-779.

Aruoba, S. B., F. X. Diebold, and C. Scotti (2009). Real-Time Measurement of Business Conditions. Journal of Business \& Economic Statistics 27(4), 417-427.

Bai, J. and S. Ng (2013). Principal components estimation and identification of static factors. Journal of Econometrics 176(1), $18-29$.

Bai, J. and P. Wang (2012). Identification and estimation of dynamic factor models. MPRA Paper 38434, University Library of Munich, Germany.

Balke, N. S., M. Fulmer, and R. Zhang (2015). Incorporating the Beige Book into a Quantitative Index of Economic Activity. Mimeo, Southern Methodist University.

Beaudry, P., D. Nam, and J. Wang (2011). Do Mood Swings Drive Business Cycles and is it Rational? NBER Working Papers 17651, National Bureau of Economic Research, Inc.

Beaudry, P. and F. Portier (2014). News-Driven Business Cycles: Insights and Challenges. Journal of Economic Literature 52(4), 993-1074.

Bjørnland, H. C. and L. A. Thorsrud (2015). Commodity prices and fiscal policy design: Procyclical despite a rule. Working Papers 0033, Centre for Applied Macro- and Petroleum economics (CAMP), BI Norwegian Business School.

Blei, D. M., A. Y. Ng, and M. I. Jordan (2003). Latent Dirichlet Allocation. J. Mach. Learn. Res. 3, 993-1022.

Bloom, N. (2014). Fluctuations in Uncertainty. Journal of Economic Perspectives 28(2), $153-76$.

Bry, G. and C. Boschan (1971). Cyclical Analysis of Time Series: Selected Procedures and Computer Programs. Number 71-1 in NBER Books. National Bureau of Economic Research, Inc.

Burns, A. F. and W. C. Mitchell (1946). Measuring Business Cycles. Number 46-1 in NBER Books. National Bureau of Economic Research, Inc. 
Carter, C. K. and R. Kohn (1994). On Gibbs Sampling for State Space Models. Biometrika 81(3), pp. 541-553.

Choi, H. and H. Varian (2012). Predicting the present with Google trends. Economic Record 88(s1), 2-9.

Del Negro, M. and C. Otrok (2008). Dynamic factor models with time-varying parameters: measuring changes in international business cycles. Staff Reports 326, Federal Reserve Bank of New York.

Ellis, C., H. Mumtaz, and P. Zabczyk (2014). What Lies Beneath? A Time-varying FAVAR Model for the UK Transmission Mechanism. Economic Journal 0(576), 668699.

Estrella, A. and F. S. Mishkin (1998). Predicting US recessions: Financial variables as leading indicators. Review of Economics and Statistics 80(1), 45-61.

Evans, M. D. D. (2005). Where Are We Now? Real-Time Estimates of the Macroeconomy. International Journal of Central Banking 1(2).

Foroni, C. and M. Marcellino (2013). A survey of econometric methods for mixedfrequency data. Working Paper 2013/06, Norges Bank.

Geweke, J. (1992). Evaluating the accuracy of sampling-based approaches to the calculation of posterior moments. In In BAYESIAN STATISTICS.

Griffiths, T. L. and M. Steyvers (2004). Finding scientific topics. Proceedings of the National academy of Sciences of the United States of America 101(Suppl 1), 52285235 .

Hamilton, J. D. (1989). A New Approach to the Economic Analysis of Nonstationary Time Series and the Business Cycle. Econometrica 57(2), 357-84.

Hansen, S., M. McMahon, and A. Prat (2014). Transparency and Deliberation within the FOMC: A Computational Linguistics Approach. CEP Discussion Papers 1276, Centre for Economic Performance, LSE.

Harvey, A. C. (1990). Forecasting, Structural Time Series Models and the Kalman Filter. Cambridge Books. Cambridge University Press.

Larsen, V. H. and L. A. Thorsrud (2015). The Value of News. Working Papers 0034, Centre for Applied Macro- and Petroleum economics (CAMP), BI Norwegian Business School. 
Lopes, H. F. and C. M. Carvalho (2007). Factor Stochastic Volatility with Time Varying Loadings and Markov Switching Regimes. Journal of Statistical Planning and Inference (137), 3082-3091.

Marcellino, M., M. Porqueddu, and F. Venditti (2013). Short-term GDP forecasting with a mixed frequency dynamic factor model with stochastic volatility. Temi di discussione (Economic working papers) 896, Bank of Italy, Economic Research and International Relations Area.

Mariano, R. S. and Y. Murasawa (2003). A new coincident index of business cycles based on monthly and quarterly series. Journal of Applied Econometrics 18(4), 427-443.

Nakajima, J. and M. West (2013). Bayesian Analysis of Latent Threshold Dynamic Models. Journal of Business \& Economic Statistics 31(2), 151-164.

Raftery, A. E. and S. Lewis (1992). How many iterations in the Gibbs sampler. In In BAYESIAN STATISTICS.

Soo, C. K. (2013). Quantifying Animal Spirits: News Media and Sentiment in the Housing Market. Working Paper 1200, Ross School of Business, University of Michigan.

Stock, J. H. and M. W. Watson (1988). A Probability Model of The Coincident Economic Indicators. NBER Working Papers 2772, National Bureau of Economic Research, Inc.

Stock, J. H. and M. W. Watson (1989). New indexes of coincident and leading economic indicators. In NBER Macroeconomics Annual 1989, Volume 4, NBER Chapters, pp. 351-409. National Bureau of Economic Research, Inc.

Stock, J. H. and M. W. Watson (2003). Forecasting output and inflation: The role of asset prices. Journal of Economic Literature 41(3), 788-829.

Tetlock, P. C. (2007). Giving content to investor sentiment: The role of media in the stock market. The Journal of Finance 62(3), 1139-1168.

Travis, J. B. and s. Jordà (2011). Evaluating the Classification of Economic Activity into Recessions and Expansions. American Economic Journal: Macroeconomics 3(2), $246-77$.

Zhou, X., J. Nakajima, and M. West (2014). Bayesian forecasting and portfolio decisions using dynamic dependent sparse factor models. International Journal of Forecasting 30, 963-980. 


\section{Appendices}

\section{Appendix A Data, reference cycles and topics}

The newspaper corpus and data used for Gross Domestic Product (GDP) are described in Sections 2.1 and 2.3, respectively. Different classifications of the business cycle into phases of expansions and recessions are listed in Table 2. A summary of all the estimated news topics, and the most important words associated with each topic, are reported in Table 3. The remaining data used in this analysis is obtained from Reuters Datastream, and are as follows: Spread is constructed as the difference between the 10 year benchmark rate and the interbank three month offered rate. OSEBX is (log) daily returns computed using the Oslo Stock Exchange Benchmark index. Both the Spread and OS$E B X$ variables are recorded on a daily frequency. Missing observations, during weekends, are filled using simple linear interpolation. Like for the daily newspaper topic time series, prior to estimation I smooth the series using a 60 day (backward looking) moving average filter, and standardize the resulting variables. $B C I$ is the seasonally adjusted industrial confidence indicator for the manufacturing sector in Norway, and LFS is the seasonally adjusted labour force. Both variables are recorded on a monthly frequency, and transformed to $(\log )$ monthly growth rates. The series are smoothed using a two month (backward looking) moving average filter and standardized prior to estimation.

Table 2. Reference cycles 1986 to 2014 (as estimated in Aastveit et al. (2016)). The different chronologies build on; a Bry-Boschan approach using GDP growth (BB-GDP); a univariate Markow-switching model using GDP growth $(M S-G D P)$; the Bry-Boschan approach applied to a coincident index based on inverse standard deviation weighting $(B B-I S D)$; and a multivariate Markow-swithing model $(M S-F M Q)$. For both the $B B-I S D$ and $M S-F M Q$ models six quarterly variables are included: the Brent Blend oil price, employment in mainland Norway, household consumption, private real investment in mainland Norway, exports of traditional goods and GDP for mainland Norway. See Aastveit et al. (2016), and the references therein, for more formal model, data, and estimation descriptions.

\begin{tabular}{llcccc}
\hline & & BB-GDP & MS-GDP & BB-ISD & MS-FMQ \\
\hline \multirow{2}{*}{$1986-1989$} & Peak & 1987:Q2 & 1986:Q2 & 1987:Q4 & 1987:Q2 \\
& Trough & 1989:Q3 & & 1989:Q1 & \\
& Peak & & & 1991:Q1 & \\
& & 1991:Q4 & 1991:Q4 & 1991:Q4 \\
$1990-1994$ & Trough & & 2001:Q1 & 2001:Q1 & 2001:Q1 \\
& Peak & 2001:Q1 & 2001:Q3 & 2001:Q3 & 2001:Q3 \\
& Trough & 2001:Q3 & 2002:Q2 & & 2002:Q3 \\
& Peak & & 2002:Q4 & & 2003:Q1 \\
& Trough -2003 & & 2007:Q4 & 2007:Q4 & 2008:Q2 \\
& 2008:Q2 & 2010:Q1 & 2009:Q1 & 2009:Q3 \\
\hline
\end{tabular}


Table 3. Estimated topics and labeling. The topics are labeled based on the meaning of the most important words, see the text for details. The "Corr" column reports the topics' correlation (using the $D_{1}^{f}$ data set, see Section 2.2) with linearly interpolated daily $G D P^{a}$ (the correlation rank is reported in parenthesis). The words are translated from Norwegian to English using Google Translate.

\begin{tabular}{|c|c|c|c|}
\hline Topic & Label & Corr & First words \\
\hline Topic 0 & Calender & $0.03(69)$ & $\begin{array}{l}\text { january, march, october, september, novem- } \\
\text { ber, february }\end{array}$ \\
\hline Topic 1 & Family business & $0.18(19)$ & $\begin{array}{l}\text { family, foundation, name, dad, son, fortune, } \\
\text { brothers }\end{array}$ \\
\hline Topic 2 & Institutional investing & $0.10(39)$ & $\begin{array}{l}\text { fund, investments, investor, return, risk, capi- } \\
\text { tal }\end{array}$ \\
\hline Topic 3 & Justice & $0.04(65)$ & $\begin{array}{l}\text { lawyer, judge, appeal, damages, claim, } \\
\text { supreme court }\end{array}$ \\
\hline Topic 4 & Surroundings & $0.18(18)$ & $\begin{array}{l}\text { city, water, meter, man, mountain, old, out- } \\
\text { side, nature }\end{array}$ \\
\hline Topic 5 & Housing & $0.14(29)$ & $\begin{array}{l}\text { housing, property, properties, apartment, } \\
\text { square meter }\end{array}$ \\
\hline Topic 6 & Movies/Theater & $0.08(50)$ & $\begin{array}{l}\text { movie, cinema, series, game, producer, prize, } \\
\text { audience }\end{array}$ \\
\hline Topic 7 & Argumentation & $0.11(34)$ & $\begin{array}{l}\text { word, besides, interesting, i.e., in fact, sure, } \\
\text { otherwise }\end{array}$ \\
\hline Topic 8 & Unknown & $0.09(42)$ & $\begin{array}{l}\text { road, top, easy, hard, lift, faith, outside, strug- } \\
\text { gle,fast }\end{array}$ \\
\hline Topic 9 & Agriculture & $0.03(68)$ & $\begin{array}{l}\text { industry, support, farmers, export, produc- } \\
\text { tion, agriculture }\end{array}$ \\
\hline Topic 10 & Automobiles & $0.18(17)$ & $\begin{array}{l}\text { car, model, engine, drive, volvo, ford, møller, } \\
\text { toyota }\end{array}$ \\
\hline Topic 11 & USA & $0.09(47)$ & $\begin{array}{l}\text { new york, dollar, wall street, president, usa, } \\
\text { obama, bush }\end{array}$ \\
\hline Topic 12 & Banking & $0.00(80)$ & $\begin{array}{l}\text { dnb nor, savings bank, loss, brokerage firm, } \\
\text { kreditkassen }\end{array}$ \\
\hline Topic 13 & Corporate leadership & $0.05(59)$ & $\begin{array}{l}\text { position, chairman, ceo, president, elected, } \\
\text { board member }\end{array}$ \\
\hline Topic 14 & Negotiation & $0.04(61)$ & $\begin{array}{l}\text { solution, negotiation, agreement, alternative, } \\
\text { part, process }\end{array}$ \\
\hline Topic 15 & Newspapers & $0.22(9)$ & $\begin{array}{l}\text { newspaper, media, schibsted, dagbladet, jour- } \\
\text { nalist, vg }\end{array}$ \\
\hline Topic 16 & Health care & $0.00(77)$ & $\begin{array}{l}\text { hospital, doctor, health, patient, treatment, } \\
\text { medication }\end{array}$ \\
\hline Topic 17 & IT systems & $0.17(24)$ & $\begin{array}{l}\text { it, system, data, defense, siem, contract, tan- } \\
\text { berg, deliver }\end{array}$ \\
\hline Topic 18 & Stock market & $0.23(8)$ & $\begin{array}{l}\text { stock exchange, fell, increased, quote, stock } \\
\text { market }\end{array}$ \\
\hline
\end{tabular}


Table 3 - continued from previous page

\begin{tabular}{|c|c|c|c|}
\hline Topic & Label & Corr & First words \\
\hline Topic 19 & Macroeconomics & $0.07(53)$ & $\begin{array}{l}\text { economy, budget, low, unemployment, high, } \\
\text { increase }\end{array}$ \\
\hline Topic 20 & Oil production & $0.18(20)$ & $\begin{array}{l}\text { statoil, oil, field, gas, oil company, hydro, } \\
\text { shelf, stavanger }\end{array}$ \\
\hline Topic 21 & Wage payments & $0.26(7)$ & $\begin{array}{l}\text { income, circa, cost, earn, yearly, cover, payed, } \\
\text { salary }\end{array}$ \\
\hline Topic 22 & Norwegian regions & $0.17(23)$ & $\begin{array}{l}\text { trondheim, llc, north, stavanger, troms } \varnothing \text {, lo- } \\
\text { cal, municipality }\end{array}$ \\
\hline Topic 23 & Family & $0.04(64)$ & $\begin{array}{l}\text { woman, child, people, young, man, parents, } \\
\text { home, family }\end{array}$ \\
\hline Topic 24 & Taxation & $0.03(71)$ & $\begin{array}{l}\text { tax, charge, revenue, proposal, remove, wealth } \\
\text { tax, scheme }\end{array}$ \\
\hline Topic 25 & $\mathrm{EU}$ & $0.04(62)$ & $\begin{array}{l}\text { eu, eea, commission, european, brussel, mem- } \\
\text { bership, no }\end{array}$ \\
\hline Topic 26 & Norwegian industry & $0.20(13)$ & $\begin{array}{l}\text { hydro, forest, factory, production, elkem, in- } \\
\text { dustry, produce }\end{array}$ \\
\hline Topic 27 & Unknown & $0.07(54)$ & $\begin{array}{l}\text { man, he, friend, smile, clock, evening, head, } \\
\text { never, office }\end{array}$ \\
\hline Topic 28 & Norwegian groups & $0.09(45)$ & $\begin{array}{l}\text { orkla, storebrand, merger, bid, shareholder, } \\
\text { acquisitions }\end{array}$ \\
\hline Topic 29 & UK & $0.06(57)$ & $\begin{array}{l}\text { british, london, great britain, the, of, pound, } \\
\text { england }\end{array}$ \\
\hline Topic 30 & Narrative & $0.03(72)$ & $\begin{array}{l}\text { took, did, later, never, gave, stand, happened, } \\
\text { him, began }\end{array}$ \\
\hline Topic 31 & Shipping & $0.10(36)$ & $\begin{array}{l}\text { ship, shipping, dollar, shipowner, wilhelmsen, } \\
\text { fleet, proud }\end{array}$ \\
\hline Topic 32 & Projects & $0.10(38)$ & $\begin{array}{l}\text { project, nsb, development, fornebu, en- } \\
\text { trepreneurship }\end{array}$ \\
\hline Topic 33 & Oil price & $0.11(32)$ & $\begin{array}{l}\text { dollar, oil price, barrel, oil, demand, level, } \\
\text { opec, high }\end{array}$ \\
\hline Topic 34 & Sports & $0.00(78)$ & $\begin{array}{l}\text { olympics, club, football, match, play, lilleham- } \\
\text { mer, sponsor }\end{array}$ \\
\hline Topic 35 & Organizations & $0.10(41)$ & $\begin{array}{l}\text { leader, create, organization, challenge, con- } \\
\text { tribute, expertise }\end{array}$ \\
\hline Topic 36 & Drinks & $0.13(30)$ & $\begin{array}{l}\text { wine, italy, taste, drinks, italian, fresh, fruit, } \\
\text { beer, bottle }\end{array}$ \\
\hline Topic 37 & Nordic countries & $0.04(63)$ & $\begin{array}{l}\text { swedish, sweden, danish, denmark, nordic, } \\
\text { stockholm }\end{array}$ \\
\hline Topic 38 & Airline industry & $0.21(12)$ & $\begin{array}{l}\text { sas, fly, airline,norwegian, braathens, airport, } \\
\text { travel }\end{array}$ \\
\hline Topic 39 & Entitlements & $0.02(73)$ & $\begin{array}{l}\text { municipality, public, private, sector, pension, } \\
\text { scheme }\end{array}$ \\
\hline
\end{tabular}


Table 3 - continued from previous page

\begin{tabular}{|c|c|c|c|}
\hline Topic & Label & Corr & First words \\
\hline Topic 40 & Employment conditions & $0.08(51)$ & $\begin{array}{l}\text { cut, workplace, measures, salary, labor, work- } \\
\text { ing, employ }\end{array}$ \\
\hline Topic 41 & Norwegian politics & $0.05(60)$ & $\begin{array}{l}\text { høyere, party, ap, labor party, stoltenberg, } \\
\text { parlament, frp }\end{array}$ \\
\hline Topic 42 & Funding & $0.31(3)$ & $\begin{array}{l}\text { loan, competition, creditor, loss, bankruptcy, } \\
\text { leverage }\end{array}$ \\
\hline Topic 43 & Literature & $0.01(76)$ & $\begin{array}{l}\text { book, books, read, publisher, read, author, } \\
\text { novel, wrote }\end{array}$ \\
\hline Topic 44 & Statistics & $0.27(6)$ & $\begin{array}{l}\text { count, increase, investigate, share, average, } \\
\text { decrease }\end{array}$ \\
\hline Topic 45 & Watercraft & $0.01(75)$ & $\begin{array}{l}\text { ship, boat, harbor, strait, shipowner, on } \\
\text { board, color }\end{array}$ \\
\hline Topic 46 & Results & $0.31(4)$ & $\begin{array}{l}\text { quarter, surplus, deficit, tax, group, operating } \\
\text { profit, third }\end{array}$ \\
\hline Topic 47 & $\mathrm{TV}$ & $0.12(31)$ & $\begin{array}{l}\text { tv, nrk, channel, radio, digital, program, me- } \\
\text { dia }\end{array}$ \\
\hline Topic 48 & International conflicts & $0.10(40)$ & $\begin{array}{l}\text { war, africa, irak, south, un, army, conflict, } \\
\text { troops, attack }\end{array}$ \\
\hline Topic 49 & Political elections & $0.02(74)$ & $\begin{array}{l}\text { election, party, power, politics, vote, politi- } \\
\text { cian, support }\end{array}$ \\
\hline Topic 50 & Music & $0.09(46)$ & $\begin{array}{l}\text { the, music, record, of, in, artist, and, play, cd, } \\
\text { band, song }\end{array}$ \\
\hline Topic 51 & Oil service & $0.19(14)$ & $\begin{array}{l}\text { rig, dollar, contract, option, offshore, drilling, } \\
\text { seadrill }\end{array}$ \\
\hline Topic 52 & Tourism & $0.21(11)$ & $\begin{array}{l}\text { hotel, rom, travel, visit, stordalen, tourist, } \\
\text { guest }\end{array}$ \\
\hline Topic 53 & Unknown & $0.16(26)$ & $\begin{array}{l}\text { no, ting, think, good, always, pretty, actually, } \\
\text { never }\end{array}$ \\
\hline Topic 54 & Aker & $0.11(35)$ & $\begin{array}{l}\text { aker, kværner, røkke, contract, shipyard, mar- } \\
\text { itime }\end{array}$ \\
\hline Topic 55 & Fishery & $0.16(27)$ & $\begin{array}{l}\text { fish, salmon, seafood, norway, tons, nourish- } \\
\text { ment, marine }\end{array}$ \\
\hline Topic 56 & Europe & $0.08(49)$ & $\begin{array}{l}\text { german, russia, germany, russian, west, east, } \\
\text { french, france }\end{array}$ \\
\hline Topic 57 & Law and order & $0.06(56)$ & $\begin{array}{l}\text { police, finance guards, aiming, illegal, investi- } \\
\text { gation }\end{array}$ \\
\hline Topic 58 & Business events & $0.00(79)$ & $\begin{array}{l}\text { week, financial, previous, friday, wednesday, } \\
\text { tdn, monday }\end{array}$ \\
\hline Topic 59 & Supervision & $0.10(37)$ & $\begin{array}{l}\text { report, information, financial supervision, en- } \\
\text { lightenment }\end{array}$ \\
\hline Topic 60 & Retail & $0.31(2)$ & $\begin{array}{l}\text { shop, brand, steen, rema, reitan, as, group, } \\
\text { ica, coop }\end{array}$ \\
\hline
\end{tabular}


Table 3 - continued from previous page

\begin{tabular}{|c|c|c|c|}
\hline Topic & Label & Corr & First words \\
\hline Topic 61 & Startup & $0.28(5)$ & $\begin{array}{l}\text { bet, cooperation, establish, product, party, } \\
\text { group }\end{array}$ \\
\hline Topic 62 & Food & $0.19(15)$ & $\begin{array}{l}\text { food, restaurant, salt, nok, pepper, eat, table, } \\
\text { waiter }\end{array}$ \\
\hline Topic 63 & Listed stocks & $0.11(33)$ & $\begin{array}{l}\text { shareholder, issue, investor, holding, stock ex- } \\
\text { change listing }\end{array}$ \\
\hline Topic 64 & Asia & $0.09(43)$ & $\begin{array}{l}\text { china, asia, chinese, india, hong kong, south, } \\
\text { authorities }\end{array}$ \\
\hline Topic 65 & Art & $0.09(44)$ & $\begin{array}{l}\text { picture, art, exhibition, gallery, artist, mu- } \\
\text { seum, munch }\end{array}$ \\
\hline Topic 66 & Disagreement & $0.08(52)$ & $\begin{array}{l}\text { criticism, express, asserting, fault, react, } \\
\text { should, alleging }\end{array}$ \\
\hline Topic 67 & Debate & $0.15(28)$ & $\begin{array}{l}\text { degree, debate, context, unequal, actually, } \\
\text { analysis }\end{array}$ \\
\hline Topic 68 & Life & $0.18(21)$ & $\begin{array}{l}\text { man, history, dead, him, one, live, church, } \\
\text { words, strokes }\end{array}$ \\
\hline Topic 69 & Distribution & $0.18(22)$ & $\begin{array}{l}\text { customer, post, product, offers, service, indus- } \\
\text { try, firm }\end{array}$ \\
\hline Topic 70 & Telecommunication & $0.08(48)$ & $\begin{array}{l}\text { telenor, mobile, netcom, hermansen, telia, } \\
\text { nokia, ericsson }\end{array}$ \\
\hline Topic 71 & IT technology & $0.21(10)$ & $\begin{array}{l}\text { internet, net, pc, microsoft, technology, ser- } \\
\text { vices, apple }\end{array}$ \\
\hline Topic 72 & Monetary policy & $0.33(1)$ & $\begin{array}{l}\text { interest rate, central bank, euro, german, in- } \\
\text { flation, point }\end{array}$ \\
\hline Topic 73 & Education & $0.04(66)$ & $\begin{array}{l}\text { school, university, student, research, professor, } \\
\text { education }\end{array}$ \\
\hline Topic 74 & Government regulations & $0.03(70)$ & $\begin{array}{l}\text { rules, authorities, competition, regulations, } \\
\text { bans }\end{array}$ \\
\hline Topic 75 & Trade organizations & $0.16(25)$ & $\begin{array}{l}\text { lo, nho, members, forbund, strike, organiza- } \\
\text { tion, payroll }\end{array}$ \\
\hline Topic 76 & Fear & $0.04(67)$ & $\begin{array}{l}\text { fear, emergency, hit, severe, financial crisis, } \\
\text { scared }\end{array}$ \\
\hline Topic 77 & Fiscal policy & $0.19(16)$ & $\begin{array}{l}\text { suggestions, parliamentary, ministry, selec- } \\
\text { tion, minister }\end{array}$ \\
\hline Topic 78 & Energy & $0.05(58)$ & $\begin{array}{l}\text { energy, emissions, statkraft, industry, environ- } \\
\text { ment }\end{array}$ \\
\hline Topic 79 & Foreign & $0.07(55)$ & $\begin{array}{l}\text { foreign, abroad, japan, japanese, immigration, } \\
\text { games }\end{array}$ \\
\hline
\end{tabular}




\section{Appendix B Additional results}

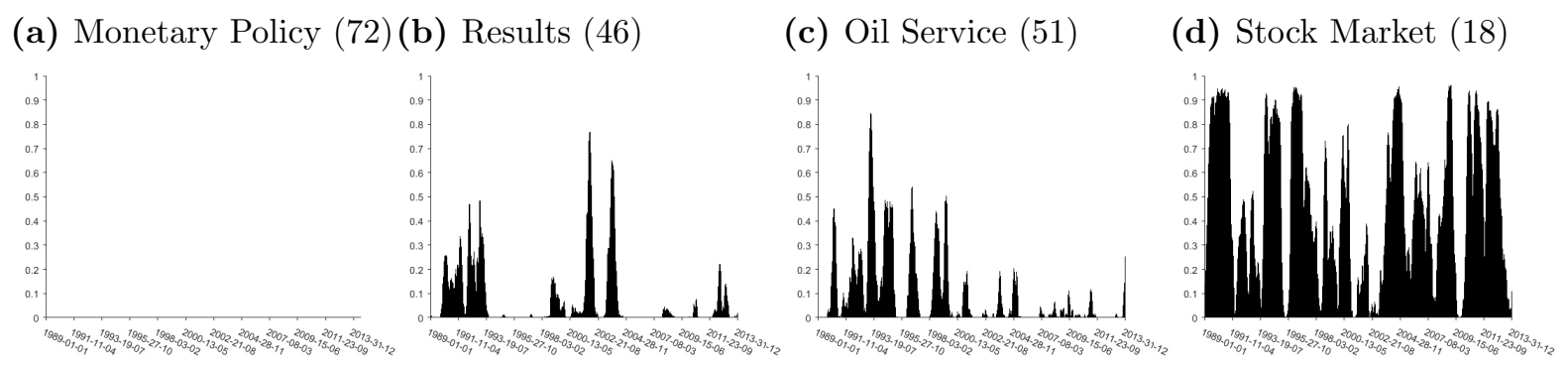

Figure 7. Topics and threshold probabilities across time (topic numbers, confer Table 3 in Appendix A, in parenthesis). Each graph reports the posterior probability that the factor loading associated with topic $i$ is 0 .
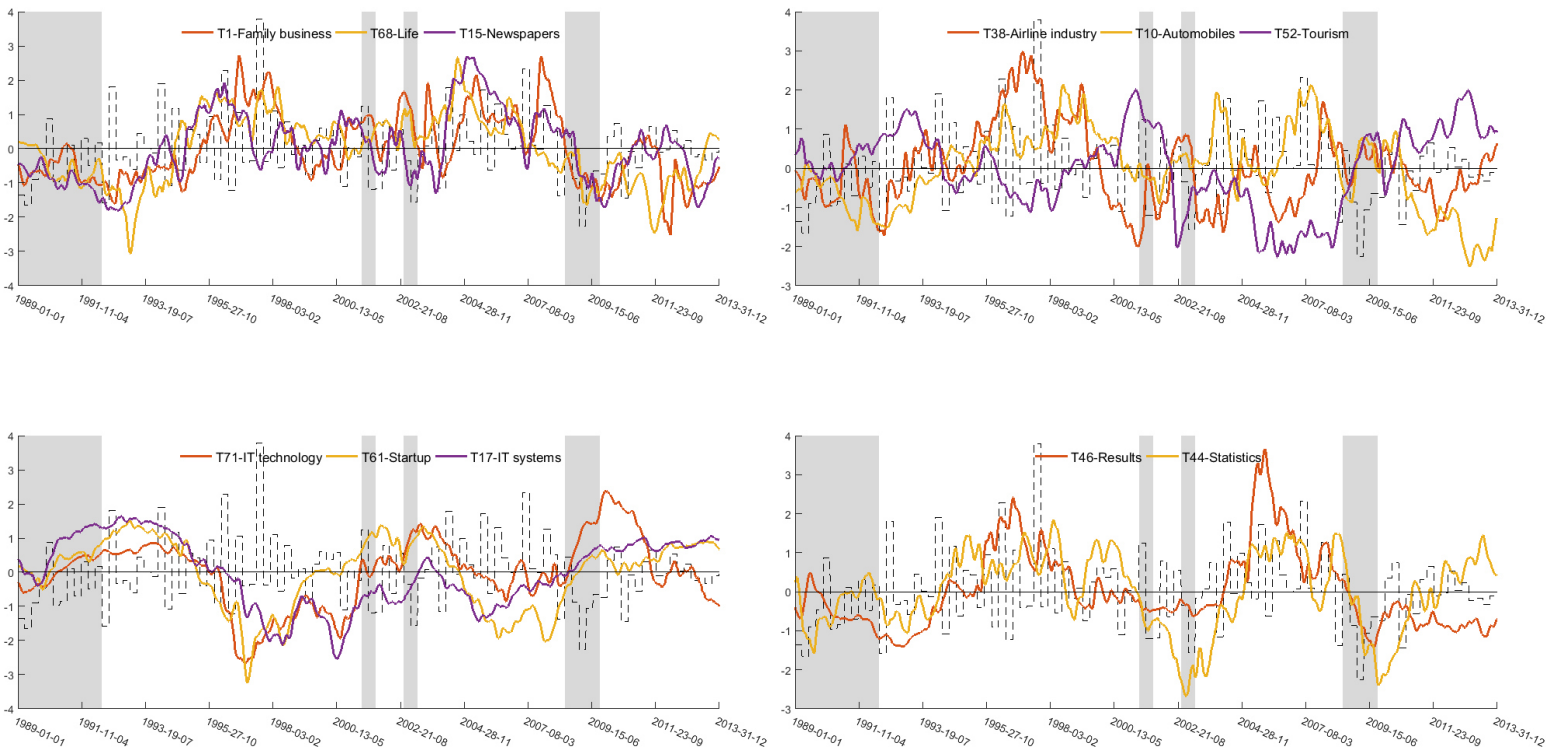

Figure 8. News topics and their (median) contribution to $N C I$ estimates across time. The news topic contributions are standardized and illustrated using different colours. $G D P^{a}$, graphed using a black dotted line, is recorded at the end of each quarter, but reported on a daily basis using previous end-ofperiod values throughout the subsequent quarter. Recession periods, defined by a $M S-F M Q$ model, see Section 4.1, are illustrated using grey colour shading. 


\section{Appendix C Filtering the news corpus}

To clean the raw textual data set a stop-word list is first employed. This is a list of common words one do not expect to have any information relating to the subject of an article. Examples of such words are the, is, are, and this. The most common Norwegian surnames and given names are also removed. In total the stop-word list together with the list of common surnames and given names removed roughly 1800 unique tokens from the corpus. Next, an algorithm known as stemming is run. The objective of this algorithm is to reduce all words to their respective word stems. A word stem is the part of a word that is common to all of its inflections. An example is the word effective whose stem is effect. Finally, a measure called $t f-i d f$, which stands for term frequency - inverse document frequency, is calculated. This measures how important all the words in the complete corpus are in explaining single articles. The more often a word occurs in an article, the higher the $t f$-idf score of that word. On the other hand, if the word is common to all articles, meaning the word has a high frequency in the whole corpus, the lower that word's $t f-i d f$ score will be. Around 250000 of the stems with the highest $t f-i d f$ score are kept, and used as the final corpus.

\section{Appendix D LDA estimation and specification}

The LDA model was developed in Blei et al. (2003). Here the algorithm as described in Griffiths and Steyvers (2004) is implemented. First, define $T$ as the number of topics and:

$$
P\left(w_{i}\right)=\sum_{j=1}^{T} P\left(w_{i} \mid z_{i}=j\right) P\left(z_{i}=j\right),
$$

as the probability of word $i$ occurring in a given document, and $w_{i}$ is word $i$, and $z_{i}$ is a latent variable denoting which topic word $i$ is drawn from. The term $P\left(w_{i} \mid z_{i}=j\right)$ denotes the probability that word $i$ is drawn from topic $j$, while the last term, $P\left(z_{i}=j\right)$, gives the probability of drawing a word from topic $j$ in the current document. Different documents will have different probabilities for drawing words from the various topics.

Let $D$ be the number of documents in the corpus and $W$ the number of unique words. The importance of the words for the different topics can then be represented as:

$$
P\left(w_{i} \mid z=j\right)=\phi_{w}^{(j)}, \text { for all } j \in[1, T] \text { and } w_{i} \in\left\{w_{1}, w_{2}, \ldots, w_{W}\right\}
$$

where $\phi$ is a set of $T$ multinomial distributions over the $W$ words. The importance of a topic within a given document is defined as:

$$
P(z=j)=\theta_{j}^{(d)}, \text { for all } j \in[1, T] \text { and } d_{i} \in\left\{d_{1}, d_{2}, \ldots, d_{D}\right\}
$$


where $\theta$ is a set of $D$ multinomial distributions over the $T$ topics.

Given $D, T$, and $W$, the goal is to obtain estimates of $\phi$ and $\theta$ that maximizes equation (11) for all $i$, i.e., the probability that a word appears in the corpus. However, this approach is susceptible to problems involving local maxima and slow convergence. Following Griffiths and Steyvers (2004), Bayesian estimation and Gibbs simulations is used instead. This strategy for discovering topics does not treat $\phi$ and $\theta$ as parameters to be estimated, but instead tries to approximate the posterior distribution over the assignments of words to topics, $P(z \mid w)$. Estimates of $\phi$ and $\theta$ are then obtained by examining the posterior distribution.

A complete probabilistic representation of the LDA model is:

$$
\begin{aligned}
w_{i} \mid z_{i}, \phi^{\left(z_{i}\right)} & \sim \operatorname{Discrete}\left(\phi^{\left(z_{i}\right)}\right) \\
\phi & \sim \operatorname{Dirichlet}(\beta) \\
z_{i} \mid \theta^{\left(d_{i}\right)} & \sim \operatorname{Discrete}\left(\theta^{\left(d_{i}\right)}\right) \\
\theta & \sim \operatorname{Dirichlet}(\alpha)
\end{aligned}
$$

where $\alpha$ and $\beta$ are hyper-parameters specifying the prior distribution for $\phi$ and $\theta$. Since these priors are conjugate, we can integrate them out of the joint distribution $P(w, z)=$ $P(w \mid z) P(z)$, using the representation in (14), and use the resulting distribution to approximate the conditional posterior:

$$
P(z \mid w)=\frac{P(w, z)}{\sum_{j=1}^{T} P\left(w, z_{j}\right)}
$$

I refer to Griffiths and Steyvers (2004) for specific details on how this is done using Gibbs simulations, and on how estimates of $\phi$ and $\theta$ can be obtained from the posterior.

Before estimation three parameters need to be pre-defined: the number of topics, $T$, and the two hyper-parameters of the Dirichlet priors, $\alpha$ and $\beta$. The two latter are defined as a function of $T$ and the number of unique words:

$$
\alpha=\frac{50}{T}, \text { and } \beta=\frac{200}{W} .
$$

which also is the same prior specification as used in Griffiths and Steyvers (2004).

\section{Appendix E The Dynamic Factor model and estima- tion}

For estimation the Dynamic Factor Model described in Section 3 is re-written to incorporate the latent threshold mechanism for the time-varying factor loadings and the mixed 
frequency variables. For notational simplicity, I assume in the following that $s=0$ (as in the benchmark model), $h=1$, and $p=1$. Moreover, I describe a model structure which includes both one quarterly and monthly variable, i.e., $N^{q}=1$ and $N^{m}=1$, in addition to a $N^{d} \times 1$ vector of daily observables. Accordingly, the system used for estimation can be written in matrix form as:

$$
\begin{aligned}
& Y_{t}=Z_{t} A_{t}+E_{t} \\
& A_{t}=F_{t}^{\Phi} A_{t-1}+R V_{t} \\
& E_{t}=F^{\Phi} E_{t-1}+U_{t}
\end{aligned}
$$

where

$$
\begin{aligned}
& Y_{t}=\left[\begin{array}{c}
y_{t, 1}^{q} \\
y_{t, 1}^{m} \\
y_{t, 1}^{d} \\
y_{t, 2}^{d} \\
\vdots \\
y_{t, N^{d}}^{d}
\end{array}\right] \quad Z_{t}=\left[\begin{array}{ccc}
1 & 0 & 0 \\
0 & 1 & 0 \\
0 & 0 & 1 \\
0 & 0 & z_{t, 2} \\
\vdots & \vdots & \vdots \\
0 & 0 & z_{t, N^{d}}
\end{array}\right] \quad A_{t}=\left[\begin{array}{c}
C_{t, q} \\
C_{t, m} \\
a_{t, d}
\end{array}\right] \quad E_{t}=\left[\begin{array}{c}
0 \\
0 \\
e_{t, 1} \\
e_{t, 2} \\
\vdots \\
e_{t, N^{d}}
\end{array}\right] \quad F_{t}^{\Phi}=\left[\begin{array}{ccc}
\beta_{t, q} & 0 & z_{q} \Phi \\
0 & \beta_{t, m} & z_{m} \Phi \\
0 & 0 & \Phi
\end{array}\right] \\
& R=\left[\begin{array}{ccc}
1 & 0 & z_{q} \\
0 & 1 & z_{m} \\
0 & 0 & 1
\end{array}\right] \quad V_{t}=\left[\begin{array}{c}
\epsilon_{t, q} \\
\epsilon_{t, m} \\
\epsilon_{t, d}
\end{array}\right] \quad F^{\Phi}=\left[\begin{array}{ccccc}
0 & 0 & \cdots & \cdots & 0 \\
0 & 0 & \cdots & \cdots & 0 \\
\vdots & \vdots & \Phi_{1} & 0 & 0 \\
\vdots & \vdots & 0 & \ddots & 0 \\
0 & 0 & 0 & 0 & \Phi_{N^{d}}
\end{array}\right] \quad U_{t}=\left[\begin{array}{c}
0 \\
0 \\
u_{t, 1} \\
u_{t, 2} \\
\vdots \\
u_{t, N^{d}}
\end{array}\right]
\end{aligned}
$$

Here, $q, m$, or $d$ superscripts denote that the variable is observed on a quarterly, monthly or daily frequency, repsectively, while $q, m$, or $d$ subscripts denote that the parameter or variable is associated with quarterly, monthly or daily variables, respectively. $C_{t, q}$ and $C_{t, m}$ are the quarterly and monthly cumulator variables, and $a_{t, d}$ is the daily coincident index. The error terms in $U_{t}$ and $V_{t}$ are independent and:

$$
\left.\left[\begin{array}{l}
U_{t} \\
V_{t}
\end{array}\right] \sim \text { i.i.d.N(}\left(\begin{array}{l}
0 \\
0
\end{array}\right],\left[\begin{array}{ll}
H & 0 \\
0 & \Omega
\end{array}\right]\right)
$$

where both $H$ and $\Omega$ are assumed to be diagonal. I note here that by restricting the error matrix $\Omega$ to be non singular, the model specification basically assumes that quarterly output growth contains some measurement error relative to the latent daily business cycle factor. Accordingly, identification of the latent factors, $C_{t, q}, C_{t, m}$, and $a_{t, d}$, is obtained by 
restricting the upper $3 \times 3$ block of the time-varying factor loadings matrix $Z_{t}$ to be an identity matrix.

The time-varying factor loadings are modelled as random walks following the Latent Threshold Model (LTM) idea introduced by Nakajima and West (2013), yielding the following system:

$$
\begin{aligned}
& z_{t, i}=z_{t, i}^{*} \varsigma_{t, i} \quad \varsigma_{t, i}=I\left(\left|z_{t, i}^{*}\right| \geq d_{i}\right) \\
& z_{t, i}^{*}=z_{t-1, i}^{*}+w_{t, i}
\end{aligned}
$$

for $i=2, \ldots, N^{d}$. It is assumed that the processes for each factor loading are independent. Thus, the vector of error terms $w_{t} \sim$ i.i.d. $N(0, W)$, where $W$ is assumed to be a diagonal matrix.

The model's hyper-parameters are $H, \Omega, F^{\Phi}, F_{t}^{\Phi}, W$, and $d . \beta_{t, q}$ and $\beta_{t, m}$ are quarterly and monthly indicator variables as defined by equation (10). Although time-varying, their evolution is deterministic and need not be estimated. Thus, the only time-varying parameters in the model are those in $Z_{t}$, which together with $A_{t}$, are the model's unobserved state variables. ${ }^{22}$

Estimation consists of sequentially drawing the model's unobserved state variables and hyper-parameters utilizing 4 blocks until convergence is achieved. In essence, each block involves exploiting the state space nature of the model using the Kalman filter and the simulation smoother suggested by Carter and Kohn (1994), coupled with a MetropolisHastings step to simulate the time-varying loadings. Below I describe each block in greater detail. For future reference and notational simplicity it will prove useful to define the following: $\tilde{Y}_{T}=\left[Y_{1}, \ldots, Y_{T}\right]^{\prime}, \tilde{A}_{T}=\left[A_{1}, \ldots, A_{T}\right]^{\prime}, \tilde{Z}_{T}=\left[Z_{1}, \ldots, Z_{T}\right]^{\prime}, \tilde{E}_{T}=\left[E_{1}, \ldots, E_{T}\right]^{\prime}$, and $\tilde{F}_{T}^{\Phi}=\left[F_{1}^{\Phi}, \ldots, F_{T}^{\Phi}\right]^{\prime}$.

\section{E.1 Block 1: $\tilde{A}_{T} \mid \tilde{Y}_{T}, \tilde{Z}_{T}, \tilde{E}_{T}, \tilde{F}_{T}^{\Phi}, F^{\Phi}, H, Q$}

Equations (16a) and (16b) constitute a state space system we can use to draw the unobserved state $A_{t}$ using the Carter and Kohn's multimove Gibbs sampling approach, see Section (E.5). However, to do so we need to make the errors in the observation equation conditionally i.i.d. Given knowledge of equation (16c), we can define $F^{\Phi}(L)=\left(I-F^{\Phi} L\right)$ and pre-multiply equation $(16 \mathrm{a})$ by $F^{\Phi}(L)$ to obtain the system:

$$
\begin{aligned}
Y_{t}^{*} & =Z_{t}^{*} A_{t}+U_{t} \sim N(0, H) \\
A_{t} & =F_{t}^{\Phi} A_{t-1}+R V_{t} \sim N(0, Q)
\end{aligned}
$$

where $Y_{t}^{*}=\left(I-F^{\Phi} L\right) Y_{t}, Z_{t}^{*}=\left(I-F^{\Phi} L\right) Z_{t}$, and $Q=R \Omega R^{\prime}$.

${ }^{22}$ Note that, in principle, the $z_{q}$, and $z_{m}$ hyper-parameters could have been made time-varying. However, I experience that estimation of the model then becomes much more sensitive to the prior specification, and have therefore chosen to treat them as fixed. 
Since all hyper-parameters and state variables, less $\tilde{A}_{T}$, are known (or conditionally known), we can use the equations in (18) together with Carter and Kohn's multimove Gibbs sampling approach, to sample $A_{t}$ from:

$$
\begin{aligned}
& A_{T} \mid \cdots \sim N\left(A_{T \mid T}, P_{T \mid T}^{A}\right) \quad t=T \\
& A_{t} \mid \cdots \sim N\left(A_{t \mid t, A_{t+1}}, P_{t \mid t, A_{t+1}}^{A}\right) \quad t=T-1, T-2, \cdots, 1
\end{aligned}
$$

to get $\tilde{A}_{T}$. Note here that the Kalman filter can be run straightforwardly despite the fact that the $Y_{t}^{*}$ vector contains missing values, see Harvey (1990) for details.

\section{E.2 Block 2: $\tilde{Z}_{T}, H, W, d \mid \tilde{Y}_{T}, \tilde{A}_{T}, \tilde{E}_{T}, F^{\Phi}$}

Conditionally on $\tilde{A}_{T}$ the errors in (16a) are independent across $i$. Moreover, we have assumed that the covariance matrix of $Z_{t}$ in equation (17) is diagonal. Consequently, one can draw $\tilde{Z}_{T}$ one equation at a time. As in Appendix E.1 we deal with the fact that the errors in the observation equation are not conditionally i.i.d. by applying the quasi differencing operator, $F^{\Phi}(L)=\left(I-F^{\Phi} L\right)$, to each equation. Thus, for each $i=2, \ldots, N^{d}$, we obtain the following Gaussian system:

$$
\begin{aligned}
& y_{i, t}^{*}=a_{t, d}^{*} z_{t, i}+u_{t, i} \\
& z_{t, i}=z_{t, i}^{*} \varsigma_{t, i} \quad \varsigma_{t, i}=I\left(\left|z_{t, i}^{*}\right| \geq d_{i}\right) \\
& z_{t, i}^{*}=z_{t-1, i}^{*}+w_{t, i}
\end{aligned}
$$

where $a_{t}^{*}=\left(I-F_{i}^{\Phi} L\right) a_{t, d}$, and $y_{t, i}^{*}=\left(I-F_{i}^{\Phi} L\right) y_{t, i}$.

To simulate from the conditional posterior of $z_{t, i}^{*}$ and $d_{i}$ in (20), the procedure outlined in Nakajima and West (2013) is followed. That is, conditional on all the data and hyperparameters in the model, $\tilde{a}_{T, d}, d_{i}, W_{i}$ and $H_{i}$, we draw the conditional posterior of $z_{t, i}^{*}$ sequentially for $t=1: T$ using a Metropolis-Hastings (MH) sampler. As described in Nakajima and West (2013), the MH proposals come from a non-thresholded version of the model specific to each time $t$, as follows: Fixing $\varsigma_{t, i}=1$, take proposal distribution $N\left(z_{t, i}^{*} \mid m_{t}, M_{t}\right)$ where:

$$
\begin{aligned}
M_{t}^{-1} & =u_{t, i}^{-2} a_{t, d} a_{t, d}+W_{i}^{-1}(I+1) \\
m_{t} & =M_{t}\left[u_{t, i}^{-2} a_{t, d} y_{t, i}+W_{i}^{-1}\left\{\left(z_{t-1, i}^{*}+z_{t+1, i}^{*}\right)+(I-1) z_{0, i}^{*}\right\}\right]
\end{aligned}
$$

for $t=2: T-1$. For $t=1$ and $t=T$, a slight modification is needed. Details can be found in Nakajima and West (2013). The candidate is accepted with probability:

$$
\alpha\left(z_{t, i}^{*}, z_{t, i}^{p *}\right)=\min \left\{1, \frac{N\left(y_{t, i}^{*} \mid a_{t} z_{t, i}^{p}, u_{t, i}^{2}\right) N\left(z_{t, i}^{*} \mid m_{t}, M_{t}\right)}{N\left(y_{t, i}^{*} \mid a_{t} z_{t, i}, u_{t, i}^{2}\right) N\left(z_{t, i}^{p *} \mid m_{t}, M_{t}\right)}\right\}
$$

where $z_{t, i}=z_{t, i}^{*} \varsigma_{t, i}$ is the current state, and $z_{t, i}^{p}=z_{t, i}^{p *} \varsigma_{t, i}^{p}$ is the candidate. 
The independent latent thresholds in $d_{i}$ can then be sampled conditional on the data and the hyper-parameters. For this, a direct $\mathrm{MH}$ algorithm is employed. Let $d_{i,-j}=$ $d_{i, 0: s} \backslash d_{i, j}$. A candidate is drawn from the current conditional prior, $d_{i, j}^{p} \sim U\left(0,\left|\beta_{0}\right|+K\right)$, where $K$ is described below, and accepted with probability:

$$
\alpha\left(d_{i, j}, d_{i, j}^{p}\right)=\min \left\{1, \Pi_{t=1}^{T} \frac{N\left(y_{t, i}^{*} \mid a_{t} z_{t, i}^{p}, u_{t, i}^{2}\right)}{N\left(y_{t, i}^{*} \mid a_{t} z_{t, i}, u_{t, i}^{2}\right)}\right\}
$$

where $z_{t, i}$ is the state based on the current thresholds $\left(d_{i, j}, d_{i,-j}\right)$, and $z_{t, i}^{p}$ the candidate based on $\left(d_{i, j}^{p}, d_{i,-j}\right)$.

Lastly, conditional on the data, the hyper parameters and the time-varying parameters, we can sample $H_{i}$ and $W_{i}$ using the standard inverse Wishart distributions:

$$
H_{i} \mid \cdots \sim I W\left(\bar{T}^{H}, \bar{H}_{i}\right)
$$

where $\bar{T}^{H}=T+\underline{\mathrm{T}}^{H}, \bar{H}_{i}=\left[\underline{\mathrm{H}}_{i}+\sum_{t=1}^{T} \xi_{t, i}^{H^{\prime}} \xi_{t, i}^{H}\right]$, and $\xi_{t, i}^{H}=y_{t, i}^{*}-a_{t}^{*} z_{t, i}$, and;

$$
W_{i} \mid \cdots \sim I W\left(\bar{T}^{W}, \bar{W}_{i}\right)
$$

where $\bar{T}^{W}=T+\underline{\mathrm{T}}^{W}, \bar{W}_{i}=\left[\underline{\mathrm{W}}_{i}+\sum_{t=1}^{T} \xi_{t, i}^{W^{\prime}} \xi_{t, i}^{W}\right]$ with $\xi_{t, i}^{W}=z_{t, i}^{*}-z_{t-1, i}^{*}$.

\section{E.3 Block 3: $F_{t}^{\Phi}, \Omega \mid \tilde{A}_{T}$}

Conditional on $\tilde{A}_{T}$, the transition equation in (16b) is independent of the rest of the system. While the first and second equations of (16b) do depend on the estimates of $\Phi$, the part of the transition equation associated with the daily business cycle index in (16b) is independent of the rest of the components in (16b). Accordingly, $\Phi$ and $\sigma_{\epsilon_{d}}^{2}$, the element in the lower right corner of $\Omega$, can first be simulated independently from the rest of the parameters in $(16 \mathrm{~b})$, and then $\sigma_{\epsilon_{m}}^{2}, \sigma_{\epsilon_{q}}^{2}, z_{m}$, and $z_{q}$ can be simulated conditionally on $\Phi$ and $\sigma_{\epsilon_{d}}^{2}$.

To simulate $\Phi$ and $\sigma_{\epsilon_{d}}^{2}$, we employ the independent Normal-Wishart prior:

$$
p\left(\Phi, \sigma_{\epsilon_{d}}^{2}\right)=p(\Phi) p\left(\sigma_{\epsilon_{d}}^{2}\right)
$$

where

$$
\begin{gathered}
p(\Phi)=f_{N}\left(\Phi \mid \underline{\Phi}, \underline{V}^{\Phi}\right) \\
p\left(\sigma_{\epsilon_{d}}^{2}\right)=f_{I W}\left(\sigma_{\epsilon_{d}}^{2} \mid \underline{T}^{\Omega}, \underline{\sigma_{\epsilon_{d}}^{2}}\right)
\end{gathered}
$$

The conditional posterior of $\Phi$ is:

$$
\Phi \mid \cdots \sim N\left(\bar{\Phi}, \bar{V}^{\Phi}\right)_{I[s(\Phi)]}
$$

with

$$
\bar{V}^{\Phi}=\left(\underline{V}^{-1^{\Phi}}+\sum_{t=1}^{T} a_{t-1}^{\prime} \sigma_{\epsilon_{d}}^{-2} a_{t-1}\right)^{-1}
$$




$$
\bar{\Phi}=\bar{V}^{\Phi}\left(\underline{V}^{-1^{\Phi}} \underline{\Phi}+\sum_{t=1}^{T} a_{t-1}^{\prime} \sigma_{\epsilon_{d}}^{-2} a_{t}\right)
$$

and $I[s(\Phi)]$ is an indicator function used to denote that the roots of $\Phi$ lie outside the unit circle. Further, the conditional posterior of $\sigma_{\epsilon_{d}}^{2}$ is:

$$
\sigma_{\epsilon_{d}}^{2} \mid \cdots \sim I W\left(\bar{T}^{\Omega}, \bar{\sigma}_{\epsilon_{d}}^{2}\right)
$$

with $\bar{T}^{\Omega}=\underline{T}^{\Omega}+T$, and $\bar{\sigma}_{\epsilon_{d}}^{2}=\underline{\sigma}_{\epsilon_{d}}^{2}+\sum_{t=1}^{T}\left(a_{t}-a_{t-1} \Phi\right)\left(a_{t}-a_{t-1} \Phi\right)^{\prime}$.

Once $\Phi$ and $\sigma_{\epsilon_{d}}^{2}$ are drawn, we can construct:

$$
C_{t, j}-\beta_{t, j} C_{t-1, j} \equiv C_{t, j}^{*}=z_{j} a_{t}+\epsilon_{t, j}
$$

and draw from the conditional posterior of $z_{j}$ and $\sigma_{\epsilon_{j}}^{2}$, for $j=\{q, m\}$, where:

$$
z_{j} \mid \cdots \sim N\left(\overline{z_{j}}, \bar{V}^{z_{j}}\right)
$$

with

$$
\begin{gathered}
\bar{V}^{z_{j}}=\left(\underline{V}^{-1^{z_{j}}}+\sum_{t=1}^{T} a_{t}^{\prime} \sigma_{\epsilon_{d}}^{-2} a_{t}\right)^{-1} \\
\overline{z_{j}}=\bar{V}^{z_{j}}\left(\underline{V}^{-1^{z_{j}}} \underline{z_{j}}+\sum_{t=1}^{T} a_{t}^{\prime} \sigma_{\epsilon_{j}}^{-2} C_{t, j}^{*}\right)
\end{gathered}
$$

Finally, the conditional posterior of $\sigma_{\epsilon_{j}}^{2}$ is:

$$
\sigma_{\epsilon_{j}}^{2} \mid \cdots \sim I W\left(\bar{T}^{\Omega}, \bar{\sigma}_{\epsilon_{j}}^{2}\right)
$$

with $\bar{T}^{\Omega}$ defined above, and $\bar{\sigma}_{\epsilon_{j}}^{2}=\underline{\sigma}_{\epsilon_{j}}^{2}+\sum_{t=1}^{T}\left(C_{t, j}^{*}-a_{t} z_{j}\right)\left(C_{t, j}^{*}-a_{t} z_{j}\right)^{\prime}$.

In sum, Block 3 draws from the conditional posterior of all the elements in the $F_{T}^{\Phi}$ and $\Omega$ matrices, and constructing $Q=R \Omega R^{\prime}$, used in Block 1 , is a simple matter of bookkeeping.

\section{E.4 Block 4: $\tilde{E}_{T} \mid \tilde{Y}_{T}, \tilde{A}_{T}, \tilde{Z}_{T}$ and $F^{\Phi} \mid \tilde{E}_{T}, H$}

For each observation of the $N^{d}$ daily variables we have that:

$$
e_{t, i}=y_{t, i}-z_{t, i} a_{t}
$$

Thus, conditional on $\tilde{Y}_{T}, \tilde{A}_{T}$ and $\tilde{Z}_{T}, \tilde{E}_{T}$ is observable. As above, since $\tilde{E}_{T}$ is independent across $i$, we can sample the elements of $F^{\Phi}$ in (16c) one equation at the time. As this is done in the same manner as in equations (29) to (31) of Block 3 (with the obvious change of notation), I do not repeat the equations here. 


\section{E.5 The Carter and Kohn algorithm and observation weights}

Consider a generic state space system, written in companion form, and described by:

$$
\begin{aligned}
& y_{t}=Z_{t} a_{t}+e_{t} \sim N\left(0, H_{t}\right) \\
& a_{t}=\Gamma a_{t-1}+G u_{t} \sim N\left(0, \Omega_{t}\right)
\end{aligned}
$$

where we assume $Z_{t}, \Gamma, G, H_{t}$ and $\Omega_{t}$ are known, and we wish to estimate the latent state $a_{t}$ for all $t=1, \ldots, T$. To do so, we can apply Carter and Kohn's multimove Gibbs sampling approach (see Carter and Kohn (1994)).

First, because the state space model given in equation (39) is linear and (conditionally) Gaussian, the distribution of $a_{t}$ given $\tilde{y}_{T}$ and that of $a_{t}$ given $a_{t+1}$ and $\tilde{y}_{t}$ for $t=T-1, \cdots, 1$ are also Gaussian:

$$
\begin{aligned}
a_{T} \mid \tilde{y}_{T} & \sim N\left(a_{T \mid T}, P_{T \mid T}\right), \quad t=T \\
a_{t} \mid \tilde{y}_{t}, a_{t+1} & \sim N\left(a_{t \mid t, a_{t+1}}, P_{t \mid t, a_{t+1}}\right), \quad t=T-1, T-2, \cdots, 1
\end{aligned}
$$

where

$$
\begin{aligned}
a_{T \mid T} & =E\left(a_{T} \mid \tilde{y}_{T}\right) \\
P_{T \mid T} & =\operatorname{Cov}\left(a_{T} \mid \tilde{y}_{T}\right) \\
a_{t \mid t, a_{t+1}} & =E\left(a_{t} \mid \tilde{y}_{t}, a_{t+1}\right)=E\left(a_{t} \mid a_{t \mid t}, a_{t \mid t+1}\right) \\
P_{t \mid t, a_{t+1}} & =\operatorname{Cov}\left(a_{t} \mid \tilde{y}_{t}, a_{t+1}\right)=\operatorname{Cov}\left(a_{t} \mid a_{t \mid t}, a_{t \mid t+1}\right)
\end{aligned}
$$

Given $a_{0 \mid 0}$ and $P_{0 \mid 0}$, the unknown states $a_{T \mid T}$ and $P_{T \mid T}$ needed to draw from (40a) can be estimated from the (conditionally) Gaussian Kalman filter as:

$$
\begin{aligned}
a_{t \mid t-1} & =\Gamma a_{t-1 \mid t-1} \\
P_{t \mid t-1} & =\Gamma P_{t-1 \mid t-1} \Gamma^{\prime}+G \Omega_{t} G^{\prime} \\
K_{t} & =P_{t \mid t-1} Z_{t}^{\prime}\left(Z_{t} P_{t \mid t-1} Z_{t}^{\prime}+H_{t}\right)^{-1} \\
a_{t \mid t} & =a_{t \mid t-1}+K_{t}\left(y_{t}-Z_{t} a_{t \mid t-1}\right) \\
P_{t \mid t} & =P_{t \mid t-1}-K_{t} Z_{t} P_{t \mid t-1}
\end{aligned}
$$

That is, at $t=T$, equation $42 \mathrm{~d}$ and $42 \mathrm{e}$ above, together with equation $40 \mathrm{a}$, can be used to draw $a_{T \mid T}$. Moreover, $a_{t \mid t, a_{t+1}}$ for $t=T-1, T-2, \cdots, 1$ can also be simulated based on $40 \mathrm{~b}$, where $a_{t \mid t, a_{t+1}}$ and $P_{t \mid t, a_{t+1}}$ are generated from the following updating equations:

$$
\begin{aligned}
& a_{t \mid t, a_{t+1}}=a_{t \mid t}+P_{t \mid t} \Gamma^{\prime}\left(\Gamma P_{t \mid t} \Gamma^{\prime}+G \Omega_{t} G^{\prime}\right)^{-1}\left(a_{t+1}-\Gamma a_{t \mid t}\right) \\
& P_{t \mid t, a_{t+1}}=P_{t \mid t}+P_{t \mid t} \Gamma^{\prime}\left(\Gamma P_{t \mid t} \Gamma^{\prime}+G \Omega_{t} G^{\prime}\right)^{-1} \Gamma P_{t \mid t}
\end{aligned}
$$


When computing the news topic contributions in Section 4.2 of the main paper, I decompose the state vector into a history of forecast error contributions. At each time interval $t$, the forecast error in predicting $y_{t}$ is given by $v_{t}=y_{t}-Z_{t} a_{t \mid t-1}$. In computing $a_{t \mid t}$, equation (42d) above, the Kalman gain $K_{t}$ is used to weight each forecast error when computing the updated state estimate. If the predictions of the ith observable at time $t$ is perfect, $v_{i, t}=0$ and this observation does not contribute to potential updates from $a_{t \mid t-1}$ to $a_{t \mid t}$. If the predictions of the ith observable at time $t$ is not perfect, $v_{i, t} \neq 0$, the observation will influence the updated state estimate as long as it is given weight through the $K_{t}$ matrix. As the updating equation in $42 \mathrm{~d}$ has a recursive structure, the time evolution of $a_{t \mid t}$ can easily be decomposed into a set of weighted forecast error contributions, resulting in the decompositions shown in Figures 6 and 8.

\section{E.6 Prior specification}

To implement the MCMC algorithm, and estimate the model, prior specifications for the initial state variables $A_{0}, Z_{0}$, and for the hyper-parameters $H, \Omega, F^{\Phi}, F_{t}^{\Phi}, W$, and $d$ are needed. The prior specifications used for the initial states take the following form: $A_{0} \sim N(0, I \cdot 100)$, and $Z_{0} \sim N(0, I \cdot 100)$. The priors for the hyper-parameters $\Phi$ and $\Phi$, which are part of the $F_{t}^{\Phi}$ and $F^{\Phi}$ matrices, respectively, are set to:

$$
\begin{aligned}
\underline{\Phi} & \sim N\left(\hat{\Phi}_{O L S}, V\left(\hat{\Phi}_{O L S}\right)\right) & \\
\underline{\Phi}_{i} & \sim N\left(0, I_{p} \cdot 0.5\right) & \text { for } i=1, \ldots, N^{d}
\end{aligned}
$$

where $\hat{\Phi}_{O L S}$ are the OLS estimates of an $\operatorname{AR}(h)$ using the first principal component of the daily news data set as dependent variable. $V\left(\hat{\Phi}_{O L S}\right)$ is a diagonal matrix where the non-zero entries are the variance terms associated with the $\hat{\Phi}_{O L S}$ elements. To draw $z_{q}$ and $z_{m}$, which are also part of the $F_{t}^{\Phi}$ and $F^{\Phi}$ matrices, I use: $\underline{z}_{i} \sim N(1,1)$ for $i=\{q, m\}$.

The priors for the hyper-parameters $W, H$, and $\Omega$, are all from the Inverse-Wishart distribution, where the first element in each prior distribution is the degrees of freedom parameter, and the second the scale parameter: $\underline{W}_{i} \sim I W\left(\underline{T}^{W}, \underline{T}^{W} \cdot \kappa_{W}^{2}\right)$ where $\underline{T}^{W}=8000$ and $\kappa_{W}=0.003$ for $i=1, \ldots, N^{d} ; \underline{H}_{i} \sim I W\left(\underline{T}^{H}, \underline{T}^{H} \cdot \kappa_{H}^{2}\right)$ where $\underline{T}^{H}=1000$ and $\kappa_{H}=0.3$ for all the $i$ non zero diagonal elements of $H$; $\underline{\Omega}_{i} \sim I W\left(\underline{T}^{\Omega}, \underline{T}^{\Omega} \cdot \kappa_{\Omega}^{2}\right)$ where $\underline{T}^{\Omega}=100$ and $\kappa_{\Omega}=0.2$ for $i=\{q\}$, and $\underline{T}^{\Omega}=10000$ and $\kappa_{\Omega}=0.01$ for $i=\{m, d\}$. In sum, these priors are very informative for the variance of the time-varying factor loadings and for the measurement errors $\left(\underline{\Omega}_{i}\right.$ and $\left.\underline{H}_{i}\right)$, but not for the law of motion for the latent business cycle index.

Finally, to draw the latent threshold, $d$, using the algorithm described in Appendix E.2, the $K$ parameter needs to be set. $K$ controls our prior belief concerning the marginal sparsity probability. For example, assuming that a time-varying parameter follows $B_{t} \sim$ 
$N\left(0, v^{2}\right)$, and marginalizing over $B_{t}$, it can be shown that $\operatorname{Pr}\left(\left|B_{t}\right|=0\right)=2 \Phi\left(\frac{d}{v}\right)-1$, where $\Phi$ is the standard normal CDF. Defining $K=\frac{d}{v}$ as the standardized scaling parameter with respect to the threshold, it can be seen that $K=3$ implies a marginal sparsity probability exceeding 0.99. As described in Nakajima and West (2013), a neutral prior will support a range of sparsity values in order to allow the data to inform on relevant values, and they suggest that setting $K=3$ is a reasonable choice. ${ }^{23}$ However, in contrast to in Nakajima and West (2013), where the time-varying parameters follows AR(1) dynamics, the timevarying factor loadings in (20) follows independent random walk processes. The random walk is non-stationary, and does not have a marginal distribution. For this reason I have experimented with estimating the model using different values for $K$, finding that higher values for $K$, coupled with the rather tight priors for the variance of the factor loadings, results in worse model performance (in terms of ROC and AUROC scoring). Accordingly, $K=0.05$, in the estimations conducted in this analysis.

\section{E.7 Convergence of the Markov Chain Monte Carlo Algorithm}

Table 4 summarizes the main convergence statistics used to check that the Gibbs sampler mixes well. In the first row of the table the mean, as well as the minimum and maximum, of the 10th-order sample autocorrelation of the posterior draws is reported. A low value indicates that the draws are close to independent. The second row of the table reports the relative numerical efficiency measure (RNE), proposed by Geweke (1992). The RNE measure provides an indication of the number of draws that would be required to produce the same numerical accuracy if the draws represented had been made from an i.i.d. sample drawn directly from the posterior distribution. An RNE value close to or below unity is regarded as satisfactory. Autocorrelation in the draws is controlled for by employing a 4 percent tapering of the spectral window used in the computation of the RNE. The last row, labelled IRL, reports the mean of the i-statistic. This statistic was proposed by Raftery and Lewis (1992). In essence, it measures the ratio of two other statistics: the total number of draws needed to achieve the desired accuracy for each parameter, and the number of draws that would be needed if the draws represented an i.i.d. chain, see Raftery and Lewis (1992) for details. ${ }^{24}$ Values of IRL exceeding 5 indicate convergence problems with the sampler.

As can be seen from the results reported in Table 4, the sampler seems to have converged. That is, the mean autocorrelations are all very close to zero, and the minimum or

\footnotetext{
${ }^{23}$ Note that when combined with the priors over the other hyper-parameters in the model, the implied marginal prior for each threshold will not be uniform, see Nakajima and West (2013) for details.

${ }^{24}$ The parameters used for computing these diagnostics are as follows: quantile $=0.025$; desired accuracy $=0.025$; required probability of attaining the required accuracy $=0.95$.
} 
Table 4. Convergence statistics. The AutoCorr row reports the 10th-order sample autocorrelation of the draws, the $R N E$ row reports the relative numerical efficiency measure, proposed by Geweke (1992), while the $I R L$ row reports the i-statistic, proposed by Raftery and Lewis (1992). For each entry we report the mean value together with the minimum and maximum value obtained across all parameters in parentheses.

\begin{tabular}{|c|c|c|c|c|c|c|}
\hline \multirow[b]{2}{*}{ Statistic } & \multicolumn{6}{|c|}{ Parameters } \\
\hline & $\mathbf{H}$ & $\Omega$ & $F^{\Phi}$ & $F^{\Phi}$ & $\mathbf{W}$ & d \\
\hline AutoCorr & $\begin{array}{c}-0.0 \\
(-0.1,0.1)\end{array}$ & $\begin{array}{c}0.1 \\
(0.1,0.1)\end{array}$ & $\begin{array}{c}0.1 \\
(-0.1,0.1)\end{array}$ & $\begin{array}{c}-0.0 \\
(-0.1,0.1)\end{array}$ & $\begin{array}{c}0.0 \\
(-0.0,0.1)\end{array}$ & $\begin{array}{c}0.0 \\
(-0.2,0.1)\end{array}$ \\
\hline RNE & $\begin{array}{l}1.1 \\
(0.3,1.9)\end{array}$ & $\begin{array}{c}0.3 \\
(0.2,0.5)\end{array}$ & $\begin{array}{l}0.3 \\
(0.7,1.7)\end{array}$ & $(0.6,1.6)$ & $\begin{array}{l}0.7 \\
(0.4,1.0)\end{array}$ & $\begin{array}{l}0.9 \\
(0.4,1.5)\end{array}$ \\
\hline IRL & $\begin{array}{c}1.9 \\
(1.9,1.9)\end{array}$ & $\begin{array}{c}1.4 \\
(1.4,1.4)\end{array}$ & $\begin{array}{l}1.4 \\
(1.2,1.2)\end{array}$ & $\begin{array}{c}1.2 \\
(1.4,1.4)\end{array}$ & $\begin{array}{c}1.0 \\
(1.0,1.0)\end{array}$ & $\begin{array}{c}1.0 \\
(1.0,1.0)\end{array}$ \\
\hline
\end{tabular}

maximum values obtained seldom exceed 0.1 in absolute value. Moreover, the mean RNE statistic does not exceed unity by a large margin for any of the parameters. Finally, the IRL statistics are always well below 5 . Additional convergence results can be obtained on request.

\section{E.8 A simulation experiment}

To control the estimation procedure, and verify the code, I run a simple simulation experiment. Artificial data is generated from a data generating process like the one described in Appendix E, with $T=8769$ daily observations. $N_{q}=1, N_{m}=1$, and $N_{d}=8$, such that $N=10$. Quarterly and monthly observations are attributed across some generic year, quarters and months, such that the artificial sample contains roughly 100 and 300 observable quarterly and monthly observations, respectively.

Hyper-parameters used to simulate the data are set as follows: All diagonal elements in $W, H$, and $\Omega$ are set to $0.001,1$, and 0.5 , repsectively. The threshold parameter $d$ is set equal to 0.3 for all of the time-varying factor loadings. The autoregressive process for the law of motion for the latent daily factor, $a_{t}$, is specified with one lag and $\Phi=0.99$. The autoregressive processes for the idiosyncratic errors are specified with $\Phi_{i}=0$ for $i=1, \ldots, N^{d}$. Finally, $z_{j}=1$ for $j=\{q, m\}$, and the latent state variables in $A_{t}$ and $Z_{t}$ are initialized at zero. The prior specifications used for estimation are in expectation all set equal to the true values, but for neither specification is the degrees of freedom parameters set higher than 100 .

Figure 9 reports the estimated latent daily factor alongside the simulated factor. As is clearly seen in the figure, they are very close to being perfectly correlated. In the figure four of the estimated time-varying factor loadings, together with their simulated counterparts, are also illustrated. Again, the estimated and simulated processes are very 
Index
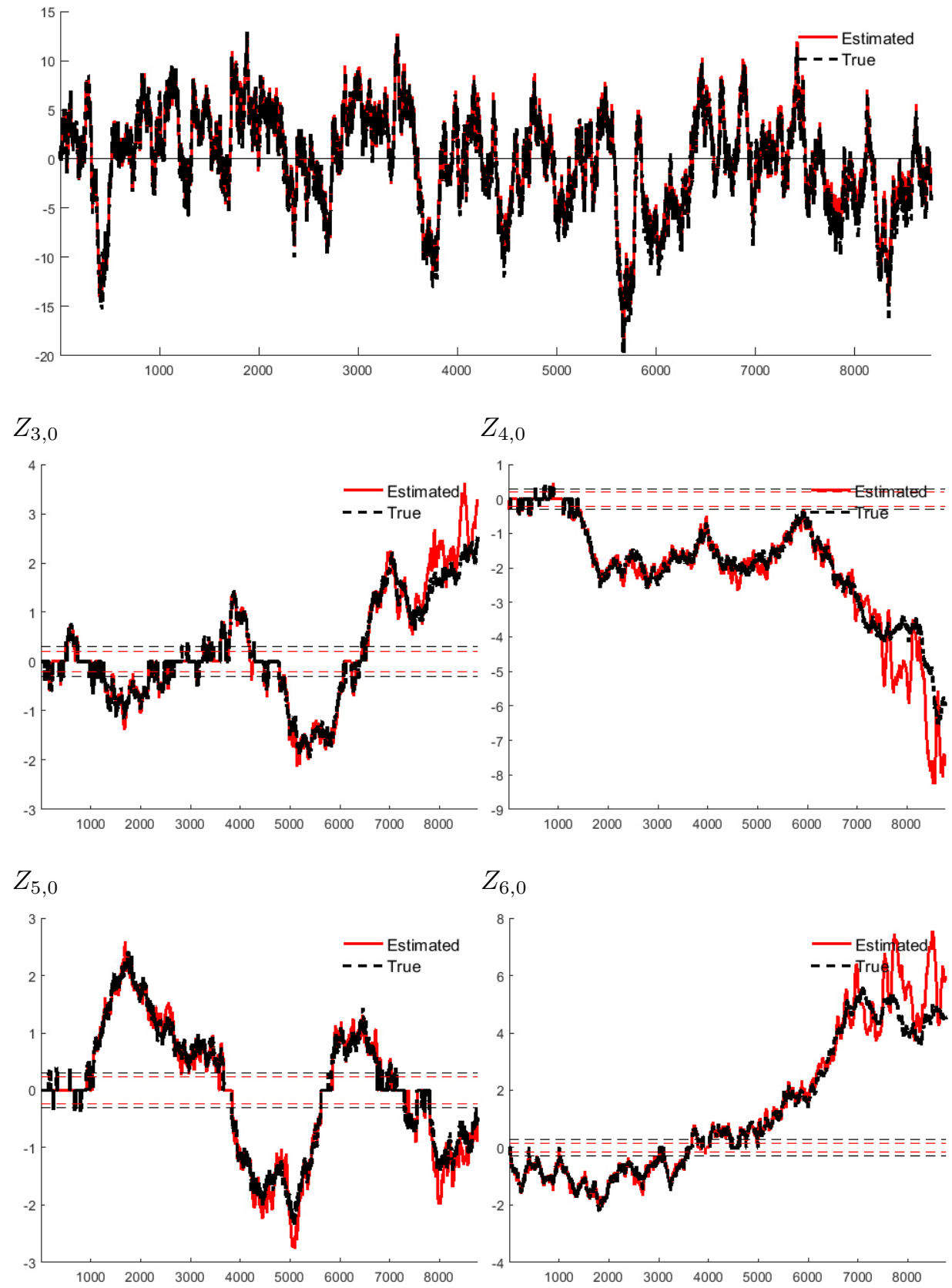

Figure 9. The upper graph reports the simulated daily index together with its estimate. The subsequent graphs report the simulated factor loadings for daily observations 3 to 6 , together with the true thresholds $(d)$ and the estimated loadings and thresholds.

similar. As seen from the figures, the estimation procedure is also capable of identifying the true threshold value with a large degree of precision. Table 5 reports the posterior median and standard deviation of the parameter estimates for $\Phi_{1}, \Omega_{3,3}$, and $H_{i}$ for $i=$ $\{3,4,5,6\}$. All estimates are precisely estimated and very close to their true values. 
Table 5. Estimates and true DGP parameters. The numbers reported in parenthesis are standard deviations. See also Figure 9.

\begin{tabular}{lcccccc}
\hline & $\Phi_{1}$ & $\Omega_{3,3}$ & $H_{3,3}$ & $H_{4,4}$ & $H_{5,5}$ & $H_{6,6}$ \\
\hline Estimated & 0.99 & 0.48 & 1.29 & 1.05 & 0.99 & 1.00 \\
\multirow{3}{*}{ True } & $(0.01)$ & $(0.01)$ & $(0.02)$ & $(0.02)$ & $(0.02)$ & $(0.02)$ \\
\hline
\end{tabular}


Centre for Applied Macro - and Petroleum economics (CAMP)

will bring together economists working on applied macroeconomic issues, with special emphasis on petroleum economics.

BI Norwegian Business School

Centre for Applied Macro - Petroleum economics (CAMP)

N-0442 Oslo

http://www.bi.no/camp 